University of Rhode Island

DigitalCommons@URI

Open Access Master's Theses

1979

\title{
A STUDY OF TENANT MANAGEMENT OF PUBLIC HOUSING
}

Alan Gary Morley

University of Rhode Island

Follow this and additional works at: https://digitalcommons.uri.edu/theses

\section{Recommended Citation}

Morley, Alan Gary, "A STUDY OF TENANT MANAGEMENT OF PUBLIC HOUSING" (1979). Open Access

Master's Theses. Paper 389.

https://digitalcommons.uri.edu/theses/389

This Thesis is brought to you for free and open access by DigitalCommons@URI. It has been accepted for inclusion in Open Access Master's Theses by an authorized administrator of DigitalCommons@URI. For more information, please contact digitalcommons@etal.uri.edu. 
A STUDY OF

TENANT MANAGEMENT OF PUBLIC HOUSING

BY

ALAN GARY MORLEY

A THESIS PROJECT SUBMITTED IN PARTIAL FULFILLMENT

OF THE

REQUIREMENTS FOR THE DEGREE

OF

MASTER OF COMMUNITY PLANNING

UNIVERSITY OF RHODE ISLAND

1979 


\section{MASTER OF COMMUNITY PLANNING \\ THESIS PROJECT \\ OF \\ ALAN GARY MORLEY}

\section{Approved:}

Thesis Project

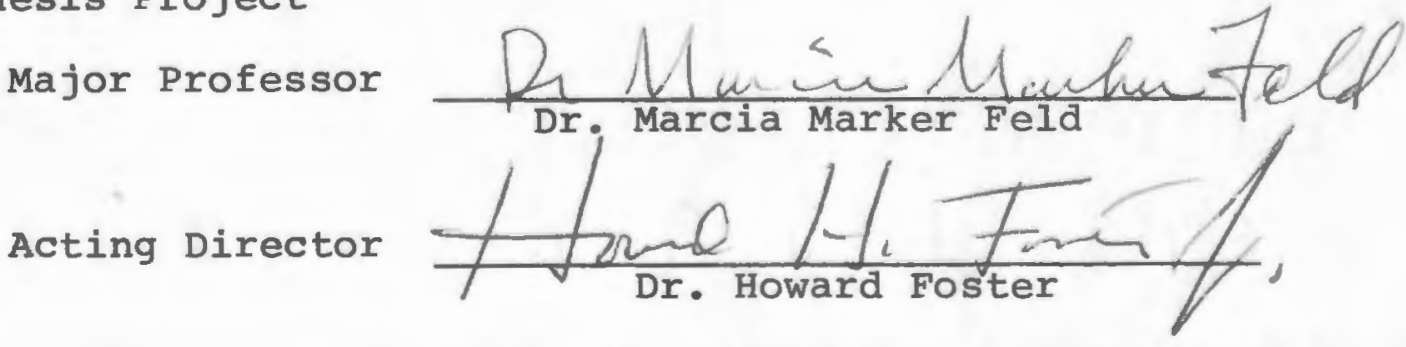

UNIVERSITY OF RHODE ISLAND

1979 


\section{THESIS PROJECT ABSTRACT}

Conventional public housing in the United states has undergone much change in the past 25 years particularly in terms of the socioeconomic characteristics of the tenants and fiscal problems. The public housing in our urban centers had originally been built for a different social and economic class of people than the ones it presently serves. Many of those former public housing tenants after World War II were able to move to the suburbs with the help of various low interest federal loans. The new residents, due to lack of financial capacity, (some due to racial discrimination in the housing market) were forced to seek housing in public housing, many as a permanent resident. High operating costs in public housing are due to a great degree to rising inflation and maintenance repairs. All of these problems have combined to produce major problems for the housing authorities to continue operating. Many large urban housing authorities are operating on negative cash flows. This study has discussed tenant management as a means of dealing with part of the problems of providing housing for low income families in conventional public housing. Two somewhat distinct approaches to tenant management were focused upon; The Bromley Heath TMC in 
Boston, Massachusetts and the St. Louis, Missouri TMC and its offsprings in Newark, New Jersey and Louisville, Kentucky .

The study traces the historical background of public housing and identifies some of the reasons for its present problems. Tenant management at Bromley-Heath and St. Louis have been analyzed as to how well each one has been able to deal with these problems. The indicators used to determine change include occupancy rates, crime statistics, maintenance, rent delinquency, and employment generation.

It was concluded that the Bromley Heath TMC had, in fact, generated some positive effects since its inception. Maintenance has improved greatly. A community security patrol had been operating on the premises and has helped reduce vandalism and procedures have been established to systematically ready units for re-rental upon becoming vacant. Forty employment opportunities have been generated for residents as well.

The St. Louis model established by Mr. Richard Baron has produced some positive changes in the rate vandalism, collection of rent, an increase in total monthly rental income to the development and removed low income tenants with rent delinquency records. These tenants were replaced with higher income tenants. "Higher" income tenants would be defined as those households with incomes above the poverty level (HEW). These households are actually 
moderate income. Some of the developments have become or are becoming higher income. In fact, the Iroquois

Homes Development in Louisville, Kentucky will be instituting a policy of steering higher (moderate) income tenants to the tenant management development to increase its monthly rental income. An economic mix may be a desirable goal but housing very low income families must be dealt with. This is the group which has traditionally been neglected and seems to be still facing problems in st. Louis, Newark and Louisville. 


\section{ACKNOWLEDGEMENTS}

I wish to express my appreciation to Dr. Marcia Marker Feld, Associate Professor of Community Planning, and major advisor, for her valuable criticism, guidance and assistance in the writing of this thesis project. Special thanks goes to Dr. Mitchell Cushman for his helpful comments on this project.

The time and cooperation which was extended to me by Tom Stitt and Michael Jacobs, both of the Boston Housing Authority, was greatly appreciated and cannot be over-expressed.

A special thanks to the various staff members of the Massachusetts Department of Community Affairs, who opened their files and provided a great deal of information to me.

My sincere gratitude is extended to my mother and father, Minna and Bernard Morley for the encouragement they gave me while writing this thesis. 
TABLE OF CONTENTS

Page

THESIS PROJECT ABSTRACT . . . . . . . . . . . iii

ACKNOWLEDGEMENTS . . . . . . . . . . . . . . . vi vi

TABLE OF CONTENTS. . . . . . . . . . . . . . . . vii

LIST OF TABLES • • . . . . . . . . . • . . . v viii

LIST OF ILLUSTRATIONS • • • . . . . • . • • • ix

CHAPTER

I. INTRODUCTION . . . . . . . . . . . . . 1

II. THE BROMLEY HEATH TENANT MANAGEMENT

CORPORATION •................ 17

Maintenance

Rent Delinquency

Security

Vacancy Rates

Administrative, Legal and Organizational

Arrangement

III. INDICATORS OF CHANGE AT BROMLEY HEATH • • . 44

Occupancy Rates

Security and Crime at Bromley Heath

Maintenance as an Indicator

IV. AN ALTERnAtive MODEL OF TENANT MANAGEMENT • 65

Legal and Administrative Structure

The National Demonstration Program for

Tenant Management

V. COMPARISON AND EVALUATIVE ANALYSIS OF THE

TWO MODELS OF TENANT MANAGEMENT . . . . . 91

VI. RECOMMENDATIONS AND CONCLUSIONS . . . . . 105

APPENDICES •. . . . . . . . . . . . . 115

BIBLIOGRAPHY • • • • • . • • • • . • • 123 
Page

1. Occupancy Rates for Bromley Heath and the Boston Housing Authority 1974-79 . . . . . . 45

2. Per Cent Changes in Occupancy Rates and Cumulative Absolute Changes in Number of Units Occupied............. . . 4 47

3. Reported Crimes Against Property and Persons for the Bromley Heath Report Area, 1973-78 . . 52

4. Selected Crimes Statistics - Team Patrol Unit for Police District Two, Boston 1975-78 • . . 55

5. Employment of Residents at Bromley Heath Through The Tenant Management Corporation $1975-78$. . . . . . . . . . . . 60

6. MOD and TPP Allocations to Participating Sites: National Tenant Management Demonstration

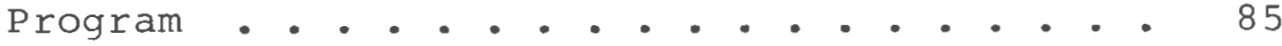

7. Occupancy Rates for Columbia Point 1974-79 • • 115

8. Service Calls for Bromley Heath Report Area 1973-78 (Selected Months) . . . . . . 120 


\section{LIST OF ILLUSTRATIONS}

Page

1. Relationships Between Low Cost Ceilings, Income Squeeze and Housing Production . . . 9

2. Income Squeeze Cycle . . . . . . . . . . 10

3. Tenant Hostility Cycle . . . . . . . . . 12

4. Selected Reported Crimes Against Property in the Bromley Heath and Mission Hill Area 1973-78 •. . . . . . . . . . . 53

5. Selected Reported Crimes Against Persons in the Bromley Heath and Mission Hill Areas . . 53

6. View of The Tenant Management Corporation Organization by The Boston Housing Authority . 116

7. Tenant Management Corporation View of The Organizational Structure . • . . • . . . 117

8. Occupancy Rates for Boston Housing Authority (minus Bromley), Columbia Point and Bromley Heath, 1974-79.............. 118

9. Yearly Total Reported Incidents of Robbery, Larceny, and Rape in the Bromley Heath Report Area 1975-78 . . . . . . . . . 118

10. Selected Reported Crimes Committed in The Bromley Heath Housing Development 1975-78 • • 119 


\section{INTRODUCTION}

Conventional public housing in most major U.S. cities is facing serious problems today. Many of the housing developments suffer from two types of pressures. One, is the deterioration of the older public housing stock; and the other is the rising costs and inflation. The deterioration of the housing stock stems, in part, from what is referred to as deferred maintenance, and is very common to projects which are suffering from financial difficulties. This occurs when management, due to insufficient funds and staff, defers repair on certain problems in order to work on other more pressing problems. There is, however, a snowballing effect from this which can increase, at a rapid pace. This will be discussed in more detail later.

The problems presented here point to several important issues which must be dealt with. Part of the problem in public housing that has contributed to its present state is the strained relationship between tenant and management. How can the cities create a better atmosphere for cooperation between these two groups? A decentralization of the management function is one such alternative which has received much discussion. This decentralization establishes the tenants as the managers 
of the public housing project, and they make many of the allocative decisions once made by the housing authority. Can tenant management of public housing begin to turn the housing projects around? Can a closer working relationship develop between the tenants and the tenant management organization? How, if at all, can this type of organization deal with what has been characterized as the "tenant hostility cycle?"

Before looking at the specific aspects of tenant management, it is important to gain an understanding of the origins of conventional public housing.

The beginnings of federal public housing date back to the passage of the Housing Act of 1937. The impetus for this legislation came from several sources. One was the labor unions, particularly the building trades. ${ }^{1}$ These $^{2}$ unions had several concerns in the passage of this legislation. Senator Robert Wagner read into the Congressional Record a resolution of the American Federation of Hosiery Workers which talked of Labor's "Double interest in the construction of low-rent dwellings" with Labor being the "representative both of the unemployed building and material workers and of low income families in need of better housing." 2 Housing reformers as well as liberal pressure groups lobbied for passage of the housing legislation. 3

During the worst years of the depression, fully one-quarter of the work force was unemployed, and the 
number of "poor people" had increased dramatically. Larry Friedman has stated:

Many of these poor people were formerly members of the middle class, who had enjoyed prosperity in the twenties. They retained their middle class culture and outlook, their articulateness and their habit of expressing their desires at the polls. There were, therefore, millions of candidates for public housing who did not belong (as later was true) to the class of the 'problem poor.' Rather, they were members of what we might call the submerged middle class.

The legislative history clearly shows that the priorities of the Housing Act of 1937 were geared to stimulate a depressed economy as well as house the "submerged middle class." Senator Robert Wagner of New York, a key legislative figure in the passage of the Act, mentioned that not everyone was intended to benefit by this legislation. He stated that, "there are some whom we cannot possibly reach; I mean those who have no means to pay the rent. - Obviously, this bill cannot provide housing for those who cannot pay the rent minus the subsidy allowed." 5 The project rents had to be sufficient to pay the operating costs of the units. The tenants were only partially subsidized.

There was a great deal of enthusiasm with the public housing program. By February, 1938, funds had been earmarked for this purpose in fifty cities in nineteen states, ${ }^{6}$ and housing projects began to be built at a rapid rate.

The pace of the program was interrupted by world War II. The efforts expended on public low rent housing 
were diverted to defense and war housing by the Defense Housing Act of 1940 .

After the war, new housing programs were created to aid the veterans and their families. The former submerged middle class could now, with FHA mortgage loans (as well as other subsidies), move to the suburbs and leave public housing behind.

From 1955 to 1970, there was a large changeover in the tenant composition of public housing as many veterans moved out of public housing. These families were replaced by underemployed and AFDC families, many of whoom increasingly sought public housing as a permanent residence because of inability to afford alternative standard housing on the private market.

Many minorities who could afford market level housing found that their options were limited to all black or all Spanish neighborhoods due to discriminatory practices of real estate brokers and landlords.

During this same period the operating costs of local housing authorities (LHA's) increased at a rate which was far greater than the rental income which remained relatively constant. A study by the Urban Institute which compared 23 urban LHA's found that four-fifths of the rise in operating costs between 1965 and 1968 was directly attributed to inflation which occurred at the rate of 8 percent annually. The aging of the housing stock accounted for only one-tenth of the increase. Tenant characteristics, such as the large number of minors and absence of wage earners, had little aggregate effect since the characteristics of fixed income families had changed little during the 1960 's. 8 
The new residents of public housing, the dependent poor, took over occupancy from the submerged middle class. "These were people displaced by urban renewal and highways, migrants from rural areas without marketable skills, and families on welfare-all with little prospect of moving on." 9

Many of these new tenants were to bring to public housing units the problems of the rural oriented person plunged into fast pace, complicated, highly organized city life. The problems were basic ones of safety, sanitation, health and the unfamiliarity with everyday necessities in an urban living environment. Items such as proper garbage disposal, knowledge of plumbing and electrical facilities presented problems for the new tenants. This is still evident to some extent, today. The Bromley Heath Housing Project in Jamaica Plain, which is the major focus of this study, seems to illustrate many of these characteristics. In a recent interview with Mildred Hailey, the Executive Director of the Bromley Heath Tenant Management Corporation, she indicated that the adaption of the southern rural poor to urban living has been extremely difficult. 10

From 1948 to 1957, non-white families increased from 37 to 48 percent of low rent projects. Between 1952 and 1957, families receiving public or private assistance and/or public benefits (other than housing) increased from 29 to 38 percent. Families with no workers increased from 26 to 31 percent, and broken families, from 25 to 27 percent. 11 
These statistics indicate that the client group being served had changed to consist of a lower income and seriously disadvantaged group; many of whom were poor, and dependent on some form of assistance for a large portion of their income.

Another important reason for the change in the characteristics of public housing tenants following the war, was the enforcement of the income limit rule for continued occupancy. Income limitations varied from city to city, but the law required a 20 percent gap between a public housing family's maximum income, and the minimum income required for a like family quartered in "decent, safe and sanitary housing" provided in the private market. Once the tenants income rose above the limits for continued occupancy, he/she was required to look for a private market unit.

An important stabilizing factor in public housing is believed to be the diversity of economic mixes. The "upwardly mobile" tenants can serve as role models for the other tenants of public housing. To require tenants to leave public housing once they reach a certain level, would defeat the possibility of creating a good, positive atmosphere. Removing the income limit rule and instituting the concept of tenant management in public housing, may provide some of the needed tools to turn public housing around. There have been some criticisms of the income limit rule. One of these is by Charles Abrams: 
Income limitations in public housing have brought no end of troubles. Some tenants have concealed their incomes, some have refused to work overtime, and some have even turned down better paying jobs. A child reaching working age may disqualify the family for continued occupancy unless he/she moves out. Where the American family boasts of financial improvement, a public housing tenant may find it the prelude to an eviction notice. The more successful occupants who could give leadership to the community are usually forced to go. . Departure of the better wage earners, white and Black, also tends to stamp the project as the haven of the poor.7

In 1967, the Department of Housing and Urban Development (HUD) developed its low rent housing modernization program. The program was instituted in 1968 and opened up a new era, not only in physical standards of housing, but also in the human relation between tenants, management and the community. The new program was an attempt to deal with two types of pressures. One was the serious deterioration of the older public housing stock. Rising costs and inflation, as well as deferred maintenance, combined to take its toll upon older public housing. A new realization that the social element of public housing must be considered, was included in this program.

This program brought about many tangible results such as the installation of new refrigerators and stoves, plastering and windows, all which was required of 15-20 years of intensive use. The Modernization Program also brought with it a better level of services to the tenants. This has partly resulted from better communication and cooperation between management and resident councils, a 
process which has been nurtured by these improvements. A resident of a project undergoing rehabilitation expressed her views about the Modernization program:

Modernization includes the rehabilitation of spirit. It isn't enough just to help the buildings, you have to help the people as well. It means we modernize the entire system. And the social benefits continue after the physical work is done.13

There are several important cycles which occur in the production, financing and management of public housing which deserve closer attention at this point in the discussion. These are the income squeeze and tenant hostility cycles. There is also the combination of law cost ceilings, income squeeze and housing production. This is another cycle which will be considered.

The first cycle in conventional public housing, which is illustrated by figure 1 , shows the relationship between low cost ceilings, income squeeze, and housing production. The combination of factors merge here to create the problems found in most public housing developments.

Due to abandonment of public housing, there is usually public pressure to spend the minimum amount necessary on construction costs in future projects. Abandonment also contributes to a shortage of housing which begets the need for production (in a tight housing market) of additional housing, but only under tight cost constraints. Because of the low cost ceilings placed on production, poorer quality materials and designs are utilized. This, in turn, leads to accelerated deterioration and the need 
for more frequent repairs. The next step in this cycle is the income squeeze problem.

\section{Figure 1}

The following diagram illustrates the relationships between low cost ceilings, income squeeze and housing production:

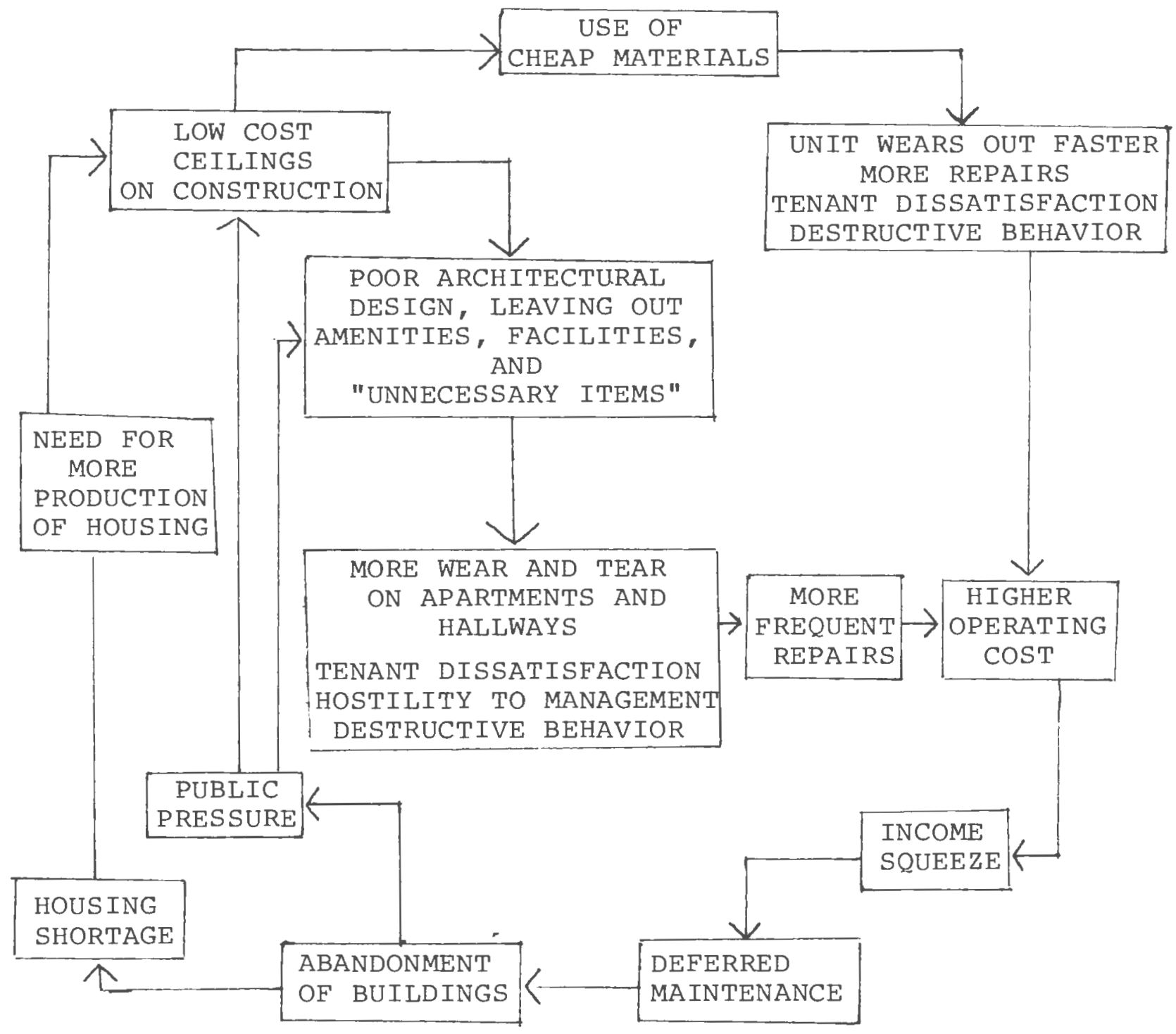

Source: Organization for Social and Technical Innovation, Cambridge, MA, 1970. 
The income squeeze cycle, shown in figure two, has many facets which compound the problems for public housing. Because of low operating budgets the maintenance staffs in public housing are usually smaller than the number of personnel required to handle the repair work. Needed repairs fall by the wayside due to the lack of staff members. This slowness to deal with repair problems is worse where there is tenant-maintenance staff hostility. The slowness of repairs, lack of funds and tenant hostility, combine to create even larger maintenance problems.

Figure 2

Income Squeeze Cycle

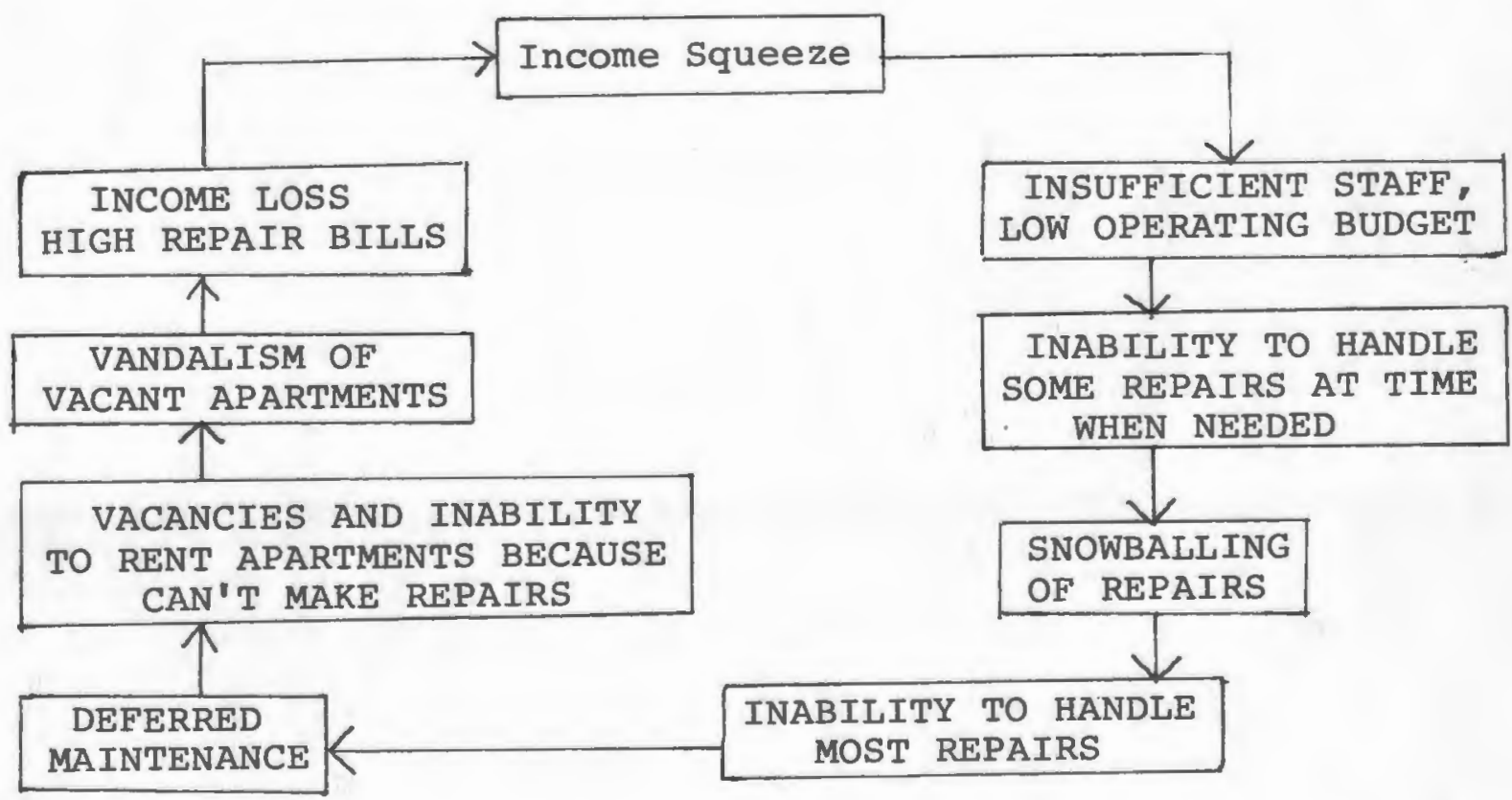

Source: Organization for Social and Technical Innovation, Cambridge, MA, 1970. 
Since the staff cannot make the necessary repairs, the dwelling units further deteriorate, and tenants often move out when conditions get extremely poor. Once tenants leave the deteriorating units, vandalism begins. Scavengers enter the apartments and steal appliances, plumbing, fixtures and anything else of value. Often, what they cannot steal, they destroy. This plunges the development further in the financial abyss lowering the potential number of rentable units, and increasing the repair and replacement costs required to rehabilitate these vandalized units.

The next cycle is the tenant hostility cycle, which is shown by figure three. It is very much interrelated to the income squeeze cycle. The tenants become hostile to the Local Housing Authority (LHA) personnel due to the feeling that management isn't concerned about the conditions of their apartments or their welfare. This animosity is usually directed toward those representatives of management with whom tenants come in to contact most frequently, such as maintenance personnel. Another type of hostility is directed towards the physical plant which results in vandalism, carelessness and indifference to the property.

The staff personnel, after being subjected to abuse, will be less inclined to work conscientiously in order to maintain the premises. In addition to possible vandalism and carelessness on the part of tenants, there is the problem of vandals from outside the development. The 
results are higher costs for upkeep, and further deterioration of the housing.

The tenant management approach is an attempt to some degree, at least, to break this vicious circle and thereby reduce operating costs created by frequent vandalism repairs. The following chapters will examine how tenant management deals with these cycles of public housing.

Figure 3

Tenant Hostility Cycle

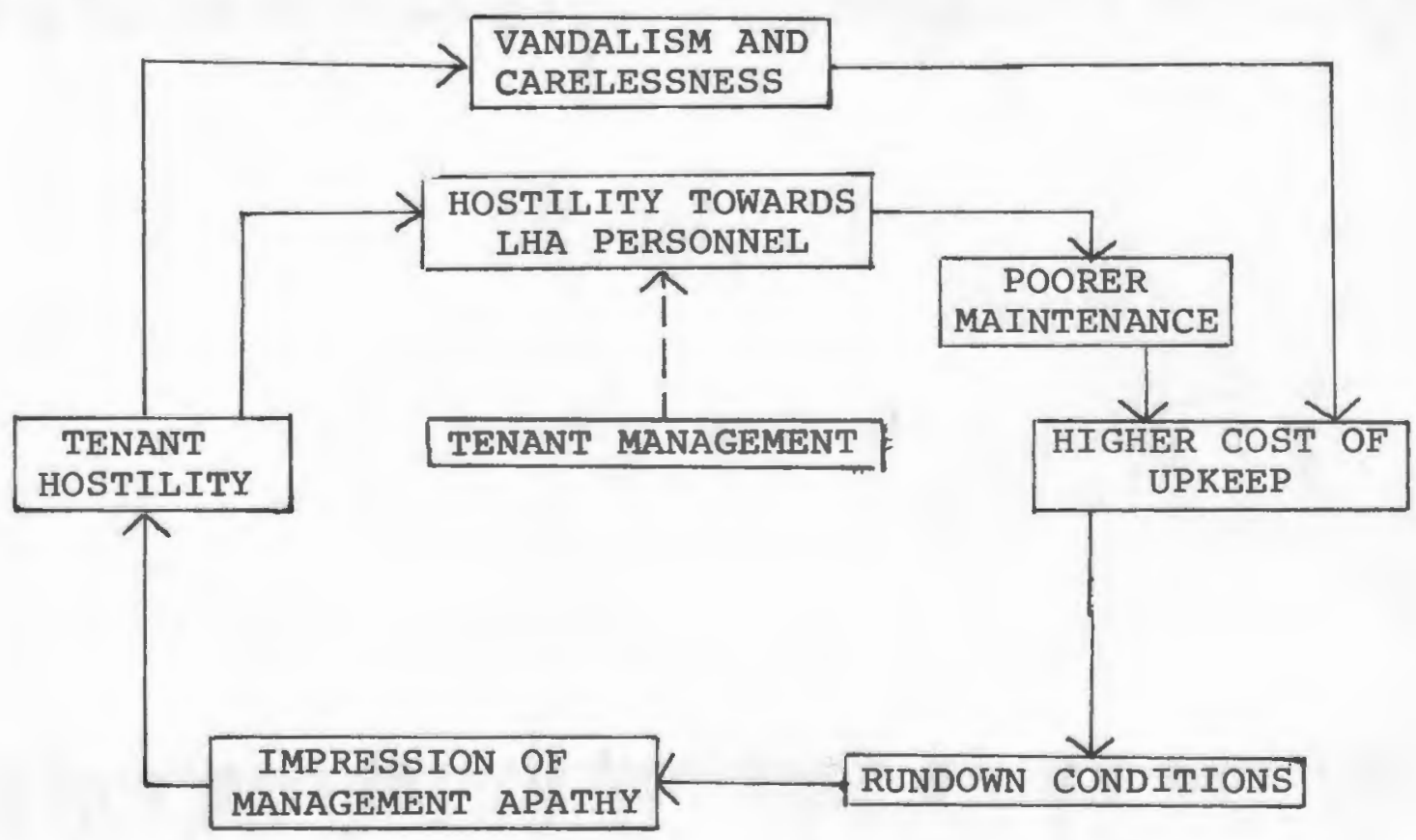

Source: Boston, Massachusetts, Massachusetts Department of Community Affairs, undated internal memo, early 1970's. 


\section{Tenant Management}

Revitalizing urban public housing cannot stop at providing adequate levels of modernization and operating funds. A management responsive and sensitive to the needs of the low income public housing residents is essential. For example, the Pruitt-Igoe housing project in St. Louis was provided with millions of dollars, yet this alone was insufficient to sustain it.

The Boston Housing Authority (BHA) entered into a management agreement with The Bromley Heath Tenant Management Corporation (TMC) in 1972. The TMC would be responsible for making decisions, many of which were previously made by the BHA central office. This change was expected to deal with the tenant hostility cycle which was a major problem at Bromley Heath as well as many other conventional urban public housing developments in the country.

The BHA has commented in an outline of its private development management program that while the past five years (1973-1978), have often seen the parties to the contract (BHA and TMC) in adversary posture, and facts are disputed that the programs quantitative success, few dispute that the TMC has been a qualitative success. Considering the relative position of the two developments after five years (Columbia Point and Bromley Heath), the general assessment would be that the TMC has indeed been a successful experiment. 14 
This paper will discuss the various aspects of the TMC at the Bromley Heath Development such as legal responsibilities, day-to-day operations and some of the programs which are planned for the future. There will also be an evaluation of some of the changes which have taken place at Bromley, both qualitative and quantitative. Also, some attention will be given to an alternative model of tenant management which was devised by Richard Baron, and has been funded by The Department of Housing and Urban Development as a demonstration project in several cities in the midwest and east. This paper will respond to questions related to the effectiveness of the tenant management model in dealing with some important dilemmas in public housing, as well as the implications for the future of housing policy in the United States. 
ENDNOTES

Chapter I

1. Timothy McDonnel1, The Wagner Housing Act:

(Chicago: Loyola University Press, 1957) . pp. 116133.

2. U.S. Congress, Senate, Senator Robert Wagner reading a resolution of the American Federation of Hosiery Workers during debate on housing legislation, 7 May 1936, Congressional Record 80:6772.

3. Lawrence M. Friedman, Government and Slum Housing, (Chicago: Rand McNally and Co., 1968), p. 104.

4. Lawrence M. Friedman, "Public Housing and the Poor", in Housing Urban America, eds. Jon Pynoos, Robert Schafer, and Chester W. Hartman, (Chicago: Aldine Publishing Co., 1973), p. 450.

5. U.S., Congress, Senate, Senator Robert Wagner speaking on proposed housing legislation. (Later to become Housing Act of 1937) 81 Cong., 2nd Session, 3 August 1937, Congressional Record 81:8099

6. Friedman, Government and Slum Housing, p. 116.

7. Richard D. Baron, Tenant Management: A Rational for a National Demonstration of Management Innovation. (St. Louis, Mo.: By the Author, 1975), p. 3.

8. Frank de Leeuw, Operating Costs in Public Housing, (Washington, D.C.: The Urban Institute, 1969). pp. 12-13. 
9. Richard D. Bingham and Samuel A. Kirkpatrick, "Providing Social Services for the Urban Poor; An Analysis of Public Housing Authorities in Large American Cities," Social Service Review 49 (March $1975): 65$.

10. Interview with Mildred Hailey, Executive Director, Bromley Heath Tenant Management Corporation, Boston, Massachusetts, 2 February 1979.

11. Friedman, Government and Slum Housing, p. 122.

12. Charles Abrams, The City is the Frontier, (New York: Harper \& Row Publishers, 1965), p. 37.

13. U.S. Department of Housing and Urban Development, HUD International Brief, XI (June, 1971), p. 11 .

14. Boston, Massachusetts, Boston Housing Authority, Department of Property Management, Private Management Program outline, (1978), p. 1 . 


\section{THE TENANT MANAGEMENT CORPORATION}

Tenant Management at the Bromley Heath Program began as a demonstration program with funding in 1968 from the then Office of Economic Opportunity (OEO). In 1968, OEO and the Boston Housing Authority (BHA) began discussion of the possibility of a tenant management demonstration program. The BHA submitted a proposal to the OEO for the grant.

The BHA, like many other authorities, was faced with a number of serious problems. The effects of inflation and rising operating costs led the list. Moreover the problem of keeping up with maintenance problems was a major burden to the authority. This led BHA to look for an alternative management approach as a potential remedy. OEO presented a $\$ 168,000$ grant to the BHA to initiate the demonstration program. The BHA, at the outset, stated "the ultimate goal of the demonstration is to develop a process to prepare tenants to assume management responsibilities through a tenant corporation with which BHA can contract management services". ${ }^{1}$

The BHA board initially approved the demonstration program for the Columbia Point housing project, considered to be one of the most problem-ridden projects in Boston. A referendum of the tenants was taken and the concept was 
rejected. The BHA sent out requests for proposals to interested tenants in other developments in Boston. Bromley-Heath submitted a proposal, and was accepted by the BHA board on June 26,1968 . The Jamaica Plain Area Planning Council (JAPAC) was designated to be the delegate agency since there was no project-wide tenant organization at that time. JAPAC was a conduit through which the funds would be channeled from OEO to whatever tenant organization would be established to carry out the demonstration program. The organization which was established was the Interim Committee. This group was drawn from organizations active in Bromley Heath, and all were tenants. This Committee entered into a contract with Trans Urban East Inc., (TUE), a consulting firm, in December 1969, to do a feasibility study of tenant management at Bromley Heath.

Early in 1970, a director of the TMC was hired by the Interim Committee. Subsequently, an Assistant Director, Community Coordinator, and Director of Research and Planning were hired. Community organizers educated the residents on the merits and responsibilities of a TMC. Building committees were established to make decisions pertaining to the priority of repairs, dealing with tenants, deterring vandalism and burglaries, and preventing unauthorized use of vacant apartments through the policing of hallways. The Tenant Management Pilot Program involved the management of five of the buildings at Bromley Heath. 
The TMC Interim Committee bore responsibility for tenant selection, eviction, employment and physical improvement within these five buildings. Maintenance men were hired to paint walls, repair windows and install new mailboxes. According to an early 1970's Department of Community Affairs memo, "The vacancy rate dropped from 25 percent to 6 percent in these five buildings." 2

In February, 1971, the TMC became incorporated. JAPAC was no longer needed as a conduit of funds. The first election was held in August of that year. Three months later six trainees, who were part of the Management Task Force, moved into the management office after completing training, while the Task Force coordinated maintenance in twelve buildings. In December 1972, the Bromley Heath Tenant Management Corporation acquired complete management responsibility for the housing project. The entire implementation process spanned a three year period. A permanent structure was devised for the TMC which included the Board which is elected from the tenant body at large. This Board meets at least once a week and publishes its progress through project bulletins.

In the next section, some of the problems which existed prior to the formation of a tenant management organization at Bromley Heath will be discussed. The following chapter will evaluate, in an analytical framework, the changes which have occurred since that time. 
The following four sections will discuss the indicators of change which will serve as measurement of progress for tenant management at Bromley Heath. However, due to data limitations it will not be possible to quantify all these indicators, and qualitative statements concerning change will be used instead. Chapter three will focus on specific quantitative changes in occupancy rates, employment generation and crime rates since the inception of tenant management.

\section{Maintenance}

The first indicator of change which will be considered is maintenance. Although it was not possible to obtain information about quantitative changes made since tenant management began, some qualitative changes have been made. The next two chapters will focus on how significant they have been since a report was issued on maintenance problems at Bromley Heath in 1970.

The Trans-Urban East (TUE) study found that "the maintenance effort of Bromley Heath is poorly conceived, inefficient, and in most areas of performance, far below standard." 3

In order to sustain adequate maintenance, it is necessary to employ a dedicated staff which performs its duties efficiently. Maintenance is a critical factor in tenant satisfaction with the overall management function in public housing. A study of housing authorities by Ahlbrandt and Brophy concluded that, 
Tenant satisfaction with maintenance is shown to be the most important component of satisfaction with management, and this dimension is based on responsiveness to maintenance problems and the quality of the work performed rather than the amount of money spent. 4

TUE found there was inefficient organization of the maintenance manpower. Maintenance employees were hired without regard to either aptitude or qualification. At the same time, there was no training program. New employees were engaged without knowledge of minimal standard operational procedures of the maintenance staff, and the techniques which could best be used to complete a job task. "The absence of a training program suggests that the maintenance effort is not taken seriously and, hence, that the daily tasks at Bromley Heath are not worthy of the new employees' best efforts." 5 Another important part of the management function is tenants' perception of how well the maintenance management staff treats them. A study conducted by The Urban Institute in 1974 found that tenants who were aware of the name of their management contact, and were able to offer resident evaluation of how well management staff treated them, correlated highly with measures of tenant satisfaction in all sizes of Large Housing Authority Groups. 6 That study also found that within the Group, greater tenant-management personal interaction was highly correlated with fewer burglaries and other crimes within the project. 7 
We can see that without a good, personal relationship between tenants and management (management staff), one could expect a breakdown in the quality of maintenance work performed, as well as rising tenants hostility towards management.

This is illustrated by an interview between a Trans-Urban East consultant and a former maintenance superintendent who expressed a general antipathy toward the residents of Bromley Heath. The superintendent had mentioned, indirectly and directly, to the members of his staff that it wasn't necessary for them to vigorously perform their work. The superintendent commented to the consultant that the tenants' complaints, poor household habits and acts of aggression committed against the maintenance crew were causes for staff hostility directed towards the tenants.

The spiraling effect of these actions is predictable. The staff, encouraged by their supervisor not to perform well, engage in poor workmanship and minimal cleaning efforts. The tenants see this as neglect and unconcern about their living environments. In turn, this leads to employee-tenant hostilities which continue to exacerbate.

The level of cooperation tenants extend to a maintenance staff can be seen as reflecting, to a large degree, tenants' pride in their development, as well as their perception of the efforts made by the maintenance staff. The problem of non-cooperation at that period is 
reflected in the following statistics for Bromley Heath during 1967-1970:

1. 6900 panes of glass broken and replaced

2. 45,000 light bulbs replaced, most had been broken

3. 200 sink supplies - many had been broken

4. 500 toilet seats replaced, most had been broken

5. 5200 fuses replaced, most had been broken8

In addition to these facts, a portion of the tenant population threw their garbage from the windows, or placed it in the hall instead of in the incinerator. clearly, this behavior was detrimental to the maintenance effort. The reasons for their acts probably had a good deal to do with the way in which the maintenance staff and manager related to the tenants.

Tenants in Bromley Heath and all BHA projects were expected to perform janitorial functions in their building. "Many Bromley Heath residents who could perform these tasks fail to do so; and the burden of their negligence falls on their neighbors, who are often justifiably unwilling to assume it." ${ }^{9}$ The result of this lack of adequate performance of janitorial work were dirty hallways and stairs, as well as offensive odors emitted from the refuse, all of which created a health hazard.

Another problem at Bromley Heath before the TMC took over management operations was the physical and verbal abuse directed at the maintenance crew by the tenants. The Trans-Urban East report stated a gang of young boys had cornered a staff member and cut off his pants. Another maintenance man had been beaten in an earlier confrontation, and was in danger of losing an eye. 
In addition to such acts, the superintendent reported his crew was continually subjected to verbal abuse from the tenants. 10 The result of this treatment reflected in inefficient work performances by the maintenance staff and the continued deterioration of the Bromley Heath project. Trans-Urban East also found other factors contributed to the problem of maintenance such as a lack of well defined maintenance procedures. The following are examples,

1. The existing procedure for care of the heating plant is haphazard. There is no routine for testing safety devices, no procedure for boiler feed water analysis; assignments for cleaning stations are not enforced; and the superintendent does not make systematic inspections of the heating plant operation. Consequently, the whole plant is dirty, unsafe, and cannot provide optimum services for tenants in the winter.

2. There is no procedure for readying a vacated apartment for re-rental. Apartments stand empty for extended periods awaiting refurbishment. While they are unattended, vandals and squatters enter them, removing major appliances and causing other damage to their interiors. Once this occurs, the rehabilitation process is more lengthy and costly than if it had been executed promptly. Some of the vacant apartments are left open to the weather. In the winter this put a damaging strain on the boiler which must be fired above a safe operating point in order to heat apartments and basements with broken windows.II

As mentioned earlier, tenants in Bromley Heath, as in all Boston Housing Authority Developments, were expected to perform janitorial functions within their buildings. This included even the elderly tenants. The supervisor at Bromley Heath hadn't provided tenants with any assistance in the necessary maintenance procedures, 
something which would seem to be a minimum responsibility of the management staff. Trans-Urban East recommended that the cleaning of halls and stairs be taken over by the maintenance staff when the staffing was adequate. Today, Bromley Heath has taken many steps toward providing better maintenance services. The majority of the maintenance staff reside in Bromley, and there does not appear to be the same type of hostility which had previously existed. Specific procedures for maintenance are followed; and tenants are no longer responsible for stair and hallway cleaning. This function is now performed by the maintenance crew which has also abated the problem of garbage accumulating in these areas.

\section{Rent Delinquency}

The second indicator selected was rent delinquency. However, since it was not possible to obtain adequate data, some general statements will be made.

Rent collection is an essential part of the function of a housing project. At Bromley Heath in 1970, the late rent payment was over 33 percent, and rent arrears amounted to $\$ 98,000 .^{12}$ At this time in the operation of the project, Bromley Heath obtained its funding from a resource pool which included all the Boston Housing Authority developments. Because of this procedure, the individual project did not feel the financial squeeze it would have if it were to operate with some degree of financial independence from the Housing Authority. 
When the Tenant Management Corporation assumed management responsibilities, one of its goals was an attempt to be more sensitive to specific problems of the tenants, especially since the TMC was comprised of tenants. They recognized the fact that individual families do suffer occasional unexpected financial reverses, and would allow for this at the time the rent was due. There were also periods during the year, such as at Christmas and "back to school," when the TMC would permit late payments or make other arrangements. At the same time, the TMC would not allow a tenant to habitually lag in rent payments.

Though the TMC inherited a large rent arrearage, for one year it made no attempt to make major push for collections, realizing that some of the arrears had progressed well beyond the tenant's ability to pay. The TMC's philosophy was that before they could make a major effort to collect back rents, it behooved them to give some specific indications that management was meeting its own responsibilities in the form of better services and improved maintenance.

The TMC began to show some beneficial changes to the tenants such as scrubbing the vacated apartments before new tenants moved in, repairing light fixtures, door knobs and the like. Previously, this type of service had not been made a standard operating procedure. At the same time, the new management began the task of picking up refuse in the halls, stairs, and courtyards, and 
painting hallways.

These were comparatively small changes, but significant in that tenants were shown that management was responsive. It was an attempt to break the managementtenant hostility cycle. After the one period of making these changes, TMC began to collect rent arrearages, but established a case by case approach. It set up a payment schedule that was reasonable for each tenant.

\section{Security}

The third indicator of change is crime and security at Bromley Heath. As will be shown, this was a major problem at the project.

The lack of adequate security at Bromley Heath prompted Trans-Urban East consultants to say, in 1970, "It is no exaggeration to say that Bromley Heath residents live in fear."13 Gangs of teenagers roamed the project harassing young children and adults alike. Narcotic rings operated openly, and people were fearful of walking outside at night because of frequent muggings.

Mechanical means of security, such as locked building entrance doors, intercoms, bars, bolts and buzzer systems were absent from Bromley, at least prior to 1970. In addition, the development lacked police protection of any type, either municipal, private or residential patrol. According to the Trans-Urban East report, Boston City Police intentionally neglected the project, which left Bromley virtually without protection of any kind. After 
the report was issued, however, efforts were made to remedy this situation. The efforts, in fact, seem to be remarkably good, as will be shown in the next chapter.

The combined security force of the Team Police unit and the resident security force has made Bromley a safe place to live. It would be an error to assume that crime is nonexistant at the development, but crime has decreased to the point that many people feel it safe enough to walk through the development at night.

A similar type of resident security patrol is in operation in Kansas City, Missouri, although this is an Authority-wide basis. In the early 1960's, the residents of public housing in Kansas City, Missouri had become alarmed over the increasing incidence of vandalism, juvenile delinquency, purse snatching, burglaries, and narcotics dealers in their projects. Together with local law enforcement officials, they organized a task force.

In October, 1971, a Director of Security was appointed, and a proposal was written which called for 70 positions. The intent was to employ "hardcore unemployables" residing in public housing. After 11 weeks of classroom training, the trainees officially began their security patrols. An article in the Journal of Housing commented, Slowly but surely, senior citizens began to venture out for fresh air and short walks. For the first time in a number of years, there was assurance of protection for them. Small children began to learn the names of security personnel and began 
talking to them or coming to them with

their problems and requests for assistance.

Delivery trucks, ice cream vendors and taxis

for the first time entered the area without

fear of being robbed.14

\section{Vacancy Rates}

The fourth indicator of change is vacancy rate changes or its inverse occupancy rates. It should be clear that any changes in the rate is attributable to many factors, and cannot be limited to only tenant management. However, a comparison of the occupancy rates for Bromley Heath with those of the Boston Housing Authority provides a basis for some indication of change. This chapter will discuss some past problems, while the following chapter will cover the actual data used for analysis.

In 1970 , there were approximately 170 vacancies in a complex of 1200 units, a 14\% vacancy rate. Although there was a substantial waiting list of over 4,000 prospective tenants, many of these vacant units were unsuitable for renting. In the report issued by TransUrban East, it was suggested that the high vacancy rate was attributable to several factors,

1. There was no procedural system for setting up an apartment once it was vacated. Bromley Heath, at this time, had no handyman to undertake minor repair work, so skilled repairman would have to be sent to accomplish minor repairs. The wage level for the skilled repairmen is much higher, and due to vandalism, the longer an apartment is vacant, the more repairs that must be done. 
2. There is a lapse between the time an apartment is vacated and the time the manager is notified it is empty. The manager hadn't set up any mechanism to reduce this delay problem. Vandalism is the consequence of delay, and the longer the time lag, the greater the damage to walls, floors, etc., as well as the probability of stolen appliances. There are also the fiscal consequences of a loss of yearly rent as well as the danger presented to tenants living in the proximity of an apartment standing vacant. These tenants feel isolated, and more vulnerable to robberies and muggings.

The report suggested several means of dealing with the problems associated with high vacancy rates. Bromley Heath has already adopted most of these into their standard operating procedures. The steps are the following,

1. Design of careful procedure for refurbishing apartments quickly.

2. A new arrangement for plastering services.

3. Closer attention by the management office to delinquencies to determine when they result from vacated apartments.

4. Tenant cooperation in the identification of vacated apartments and preventions of vandalism.16

Today, the TMC at Bromley Heath has taken a position

which states that the goal should be to obtain quality units, not just quantity of units. Given, that level of modernization funds is inadequate to properly bring all existing units up to housing code standards, it would be more practical to select certains units or building upon which to concentrate the allocation of funds and secure (board up) the others. This suggests a policy of triage. 
The concept of "triage" as used in public policy, is derived from medical terminology which is a procedure for dealing with those who are wounded. Those soldiers who are wounded seriously and diagnosed to be beyond medical attention, are not treated. The soldiers who are wounded seriously yet can be helped by medical attention, will be treated but not until those soldiers who are not seriously wounded are given medical attention.

The Boston Housing Authority has set forth a similar strategy under the Consent Degree Subplan VI Fl as required in Armando Perez et al v. the Boston Housing Authority.

"In summary, it requires an Authority-wide
reallocation of resources and placing top
priority on securing of vacant units and
correcting code violations in occupied units."17

The BHA plan would first involve an inspection of a unit prior to its being vacated. This inspection would determine what defects were caused by the tenant as well as what classification the unit should be given. The BHA has set up 4 dwelling unit classifications from "A" to "D". "A" would designate no code violations, and only minimum routine maintenance; whereas " $D$ " would require more than 200 hours of work to repair, and the unit would be secured once the tenant vacated. The Boston Housing Authority discussion paper takes a similar position, as does the Tenant Management Corporation at Bromley Heath when it states, 
It is the thesis of this paper, that it is in the best interest of the Authority to allocate its resources fully to the provision of standard dwelling units to all current lessees rather than to preparing vacant apartments for reoccupancy by new applicants. 16

\section{Administrative, Legal and Organizational Arrangement}

Under the Tenant Management Corporation

At Bromley Heath

There are 17 voting members who comprise the Board of Directors of the TMC. Twelve of these Directors are required to be members of the corporation, and the remaining five Directors are appointed by the other twelve by a majority vote. Each of the members of the Board of Directors holds office for four years. The five appointed members are considered members of the corporation ex officio.

In the first election, the first six Directors with the greatest number of votes serve for four years, and the remaining six serve for two years. This is done to stagger the number of new Directors every two years.

In each election, one of six Directors chosen is a senior citizen, while one is a youth member. The senior citizen representative is required to be at least fifty-five years old, and a resident of the Senior Citizen Development on Bickford Street. The youth member is elected in alternate years, and must not have reached his/her sixteenth birthday. 
The Board of Directors, with the approval of the Board, has the power to appoint committees and chairpersons from the corporation or the Directors. These committees act under the supervision of the Board and deal with issues determined by the Board. The standing committees are Executive, Personnel, Nominating, Finance, and Program.

Under Article XI of the By Laws of TMC, the Board of Directors has the authority to employ an Executive Director. The Executive Director is responsible for decision-making in terms of activities and procedures in order to meet the goals set forth by the Board of Directors. The Executive Director is held accountable for complaints from the Board dealing with the program level operations of the TMC and the staff personnel, and has ultimate responsibility for hiring and terminating staff personnel.

Past and Present Legal Arrangements with BHA

An essential part of making tenant management feasible is the support and cooperation of the LHA. Equally important, is enthusiasm on the part of the tenants. The BHA and TMC concurred with the conclusion of the 1972 National Association of Housing and Redevelopment Officials (NAHRO) evaluation team that the basic objective of tenant management is the imporvement of the quality of life for the residents. More explicitly, the December 21 , 1972 Tenant Management Corporation's initial contract 
defines its goals as follows:

1. To assure the low rent character of the premises.

2. To provide responsible servicing of all maintenance needs of residents.

3. To improve the environmental quality by introducing both physical and social improvements that add dignity to the neighborhood and its people.

4. To eliminate heretofor chronic vacancy problems.

5. To maintain regular rent collection.

6. To promote the addition and expansion of social programs that conform to articulated needs of the residents.19

The BHA and TMC entered into an agreement in

December 1972, to become effective January 1, 1973, where the TMC would be given authority and responsibility for management of the Bromley Heath Project. The BHA has the authority to employ independent contracts such as the TMC under the U.S. Housing Act of 1937, as amended, and Chapter $121 \mathrm{~B}$ of the Massachusetts General Laws.

It was the intent of this contract agreement that the TMC assume its management duties in a gradually increasing scale, through utilization of its own personnel.

Section 5.1 of the initial contract explains the general scope of the management duties as follows:

TMC shall, subject to the more specific description of its duties as detailed in this agreement, be responsible for the general management of the premises, including but not limited to renting apartments, making rent collections, maintaining records, keeping the premises maintained, supplied and repaired, making necessary improvements, landscaping, cleaning, promoting good tenant management relations and keeping appropriate accounts.20 
Since operating expenses for housing projects always exceeds the rental income, the Boston Housing Authority supplements the rental income in order to meet the operating expenditures. The Tenant Management Corporation, in turn, is responsible for submitting the necessary information to the BHA on a quarterly basis in order to receive subsidies.

The initial contract between the Housing Authority and the Tenant Management Corporation is in the process of being revised (March 1979), and a new contract written. The new contract will add several requirements to the reporting procedures of the TMC. For example, under Section Five, all the necessary reports required by HUD and BHA are explicitly stated, with the time frame for each one. In the previous contract, the reports were listed under three or four different sections and appendices. According to the Housing Authority, the intent now is to gain a greater accountability of program operations.

In the original contract agreement between the Housing Authority and the Bromley Heath TMC, Section 12 , which dealt with procurement, stated the following: The Tenant Management Corporation is authorized to procure and enter into contracts for supplies, materials, equipment, and services needed in the maintenance, repair and operation of the premises pursuant to the approved operating budget.21

However, in the new contract (Development Managément Agreement), and in accordance with the Housing 
Authority policy to increase accountability of the contractor and provide a clearer direction for the program, TMC will be required to comply with more detailed contractual obligations. "The Agent (TMC) must use its best efforts to standardize equipment and parts and coordinate major purchases of equipment with Authority-wide purchases wherein a savings without loss of quality can result." 22

In addition, the contract stipulates guideline and procedures for single purchases under two thousand dollars. For single purchases between $\$ 500.00$ and two thousand, the TMC is required to solicit proposals from three vendors for items which can be obtained from more than one source. The TMC also requires prior approval by the BHA for single item expenditures of over one thousand dollars. All contracts for supplies or services which exceed two thousand dollars require approval by the BHA.

One section of the contract mandates that the TMC expend its "best efforts" to utilize vendors and contractors owned by minority individuals. In the previous contract, Section 15.3 dealt with "Equal Opportunity" and explicitly mentioned non-discrimination against any employee. However, it did not refer to vendors or contractors. The wording of the new contract makes a greater effort towards creating business and employment opportunities for minority enterprises. 
The new contract makes it encumbent upon the Agent (TMC) to credit to its operating account sales tax, credits, discounts, rebates, or commissions obtained involving purchases, contracts and all other transactions pertaining to the BHA. In the initial contract there was no section which specifically mentioned this obligation. The TMC has assumed many of the responsibilities formerly possessed by the Housing Authority. The following section will discuss the areas of decision-making which have been transferred from the Housing Authority to the Bromley Heath TMC.

\section{Powers for the Tenant Management Corporation}

Terminations and Evictions

The Tenant Management Corporation has the authority to terminate a resident's tenancy when, in its judgement, sufficient cause has been shown. "Sufficient cause" is not limited to non-payment of rent. The TMC is permitted to utilize the services of its own attorney to bring action for eviction. This is an ultimate power, and is used only as a last resort. One of the staff members of the TMC commented there have been few evictions from Bromley Heath. On a case-by-case approach, the TMC will set a realistic payment schedule which a delinquent tenant can meet, instead of bringing action for eviction. The TMC believes that it is more appropriate to use all informal methods before utilizing the formal ones. 
TMC is required to conform to the same standards for tenant selection as the BHA. The procedures for compliance are given in the Tenant Selection and Assignment Plan (TSAP). All applicants for residency and transfer at Bromley Heath must be screened for eligibility and priority by the BHA Department of Occupancy. In addition, the TMC is responsible for making a serious effort to maintain a high occupancy rate.

The TMC may recommend the rejection of an applicant provided the procedure complies with the requirements of the TSAP. The reasons for rejection are required to be sent to the BHA, and the Authority will make the final determination on the proposed rejection of the applicant. However, the TMC does have the authority to develop special procedures which aren't in conflict with the TSAP, for the screening, assignment, and transfer of tenants and applicants. This also applies to procedures for hearing resident's grievances.

The TMC is also required to comply with the provisions of all federal, state and local laws prohibiting discrimination in housing. Some of these laws include Title VI of the Civil Rights Act of 1964, Executive order 11063 and Title VIII of the 1968 Civil Rights Act.

\section{Rent Collection and Tenant Status Review}

The TMC is responsible for collecting all rents when due, as well as any other charges owed to it. It is also required to reexamine the income and families living 
in Bromley Heath and compute the rent charges in accordance with HUD regulations.

\section{Social Service Program}

The TMC is authorized to provide social services provided the programs receive BHA approval. The programs' costs would be charged to the operating account of the TMC. However, most of the social services utilized by the residents of Bromley Heath are provided by outside agencies such as the Jamaica Plain Area Planning Action Council (JPAPAC), and Action for Boston Community Development (ABCD). The former agency provides services such as health care, weatherization, fuel assistance and similar programs. $A B C D$ is an economic development agency which also provides job training and other employment-related services for economically disadvantaged persons residing in Boston.

An additional agency serving Bromley Heath residents is the Social Services Center which is located within walking distance of the development. This agency provides counseling, information, referral and aid to those who utilize public assistance programs.

\section{Maintenance}

The TMC is responsible for establishing a procedure to promptly receive and investiage all service requests from residents, and maintain records of all such requests. Emergency requests are processed on a twenty-four hour basis. The TMC must report to the Housing Authority any unanticipated maintenance which is not covered by operating 
or capital budget allocations. The TMC will be reimbursed once the Housing Authority submits its approval. Emergency maintenance which is required to avoid serious threat to the health and safety of the residents or deterioration of property, can be done by the BHA. The TMC is required to report work of this nature to the BHA immediately. The subcontracting of maintenance has been dealt with in a previous portion of this section. The TMC may contract with qualified companies, subject to the approval of the BHA.

\section{Planning, Modernization and Capital Improvement}

The Housing Authority and the TMC work cooperatively to obtain funds to remedy deferred maintenance, to achieve the reasonable capital improvements necessary to enhance the physical quality and to reduce the maintenance and operating costs of the project.

\section{Rent Schedules}

The TMC is responsible for providing the Authority with the rent schedules showing maximum rentals for the different size dwelling units. The TMC is given the authority to participate in determining appropriate rent schedules for the property, provided the schedules meet federal and state requirements.

All employees who are hired to work at the Bromley Heath development are employees of the TMC, and are paid out of the development payroll account. 
The TMC is responsible for establishing an employment policy which offers residents of Bromley Heath opportunities for employment and advancement in the management and operation of the project. In addition, such opportunities are also required to be given to lower income residents in the area. The TMC is also responsible for providing the necessary training to individuals in order to qualify them for the various positions that are available. 
ENDNOTES

CHAPTER II

1. Bromley Heath Tenant Management Corporation, Narrative Document to Support Request for Refunding by the Office of Economic Opportunity, Grant No. CG 8253, (Boston, Massachusetts, 15 March 1971).

2. Massachusetts, Department of Community Affairs, Memo on the Bromley Heath TMC (undated, early $\left.1970^{\prime} \mathrm{s}\right), \mathrm{p} \cdot 1$

3. Trans Urban East Inc., Final Report Regarding the Feasibility of Tenant Management at Bromley Heath Development, (New York: By the Author, 1970), p. 5.

4. Robert S. Ahlbrandt, Jr. and Paul C. Brophy, "Management: An Important Element of the Housing Environment," Environment and Behavior, 8 (Dec. 1976): 524.

5. Trans Urban East Inc., Final Report Regarding the Feasibility of Tenant Management at Bromley Heath Development, (New York: By the Author, 1970), p. 6 .

6. Robert Saducca, et al., Management Performance in Public Housing, (Washington, D.C.: The Urban Institute, 1974), p. 51 .

7. Ibid.

8. Trans Urban East Inc., Final Report Regarding the Feasibility of Tenant Management at Bromley Heath Development, (New York: By the Author, 1970), p. 8 . 
9. Ibid.

10. Ibid., p. 9.

11. Ibid., p. 10 .

12. Ibid., p. 12 .

13. Ibid., p. 14 .

14. John E. Bridges, "Security System By the Residents, For the Residents, Under Way in Public Housing in Kansas City, Missouri," Journal of Housing (June 1973): 87.

15. Trans Urban East Inc., Final Report Regarding the Feasibility of Tenant Management at Bromley Heath Development, (New York: By the Author, 1970), p. 16.

16. Ibid., p. 18 .

17. Boston, Massachusetts, Boston Housing Authority, Discussion Paper: BHA Maintenance and Occupancy Objectives, (Feb. 1979) p. I.

18. Ibid., p. 2 .

19. Boston, Massachusetts, Boston Housing Authority, Contract Agreement between the BHA and TMC,

(21 December 1972), p. I.

20. Ibid., p. 4 .

21. Ibid., p. 13 .

22. Boston, Massachusetts, Boston Housing Authority, Private Development Management Agreement, (15 December 1978), p. 15. 


\section{INDICATORS OF CHANGE AT BROMLEY HEATH OCCUPANCY RATES}

Like most public housing developments, Bromley Heath suffers from a lack of sufficient operational and capital improvement funding. This fact is illustrated by its 65 percent occupancy rate (see Table 1). It should be recognized that although the occupancy rate was only 65 percent in February 1979, there is a conscious effort on the part of the TMC to carry out a policy of triage (see page 31) in determining recourse allocation with the present level of funding. As was mentioned earlier, instead of spreading funding over as many units as possible, the TMC has decided to produce quality units, although the quantity of livable units will be reduced.

Some have argued that in view of the long waiting list for public housing, it would be a wiser policy to produce a greater number of apartment dwellings, albeit of poorer quality. However, the District Court in Boston, through Judge Paul Garrity in Armando Perez et. al. v. the Boston Housing Authority, has ordered the Housing Authority to correct housing code violations in occupied units. Therefore, this decision has required that more monies be spent on existing units, many of which are below code standards. 
Table 1

Occupancy Rates for Bromley Heath and

The Boston Housing Authority* 1974-1979

\begin{tabular}{|c|c|c|c|c|c|c|}
\hline \multicolumn{2}{|c|}{ Total Units } & \multicolumn{2}{|c|}{ Units Occupied } & \multicolumn{2}{|c|}{ Percent Occupied } & \multirow[t]{2}{*}{ Date } \\
\hline Bromley & Boston & Bromley & Boston & Bromley & Boston & \\
\hline 1,150 & 14,733 & 912 & 13,712 & 79.3 & 93.0 & May 1974 \\
\hline 1,154 & 15,164 & 901 & 13,878 & 78.0 & 91.5 & oct. 1974 \\
\hline 1,150 & 15.162 & 877 & 13,959 & 76.0 & 92.0 & May 1975 \\
\hline 1,154 & 15,158 & 901 & 13,577 & 75.8 & 89.5 & oct. 1975 \\
\hline 1,154 & 15,360 & 872 & 13,458 & 75.5 & 87.6 & Jan. 1976 \\
\hline 1.152 & N.A. & 801 & N.A. & 69.5 & N.A. & May 1977 \\
\hline 1,124 & N.A. & 768 & N. A. & 68.3 & N.A. & oct. 1977 \\
\hline 1.124 & 15,247 & 748 & 12,825 & 66.5 & 84.0 & May 1978 \\
\hline 1,124 & 15,390 & 712 & 13,038 & 63.3 & 84.7 & oct. 1978 \\
\hline 1,130 & 15,362 & 731 & 12,454 & 65.0 & 81.0 & Feb. 1979 \\
\hline
\end{tabular}

Source: Boston, Massachusetts, Boston Housing Authority, Data from Minority Occupancy Report (1979).

* minus units in Bromley Heath

The Housing Authority has an overall occupancy rate of 81 percent (see Table 1). Included in this figure are the elderly, as well as family housing developments. Family developments have a lower occupancy rate than do elderly projects. Hence, if elderly developments were factored out, the occupancy rate would be somewhat less than 81 percent. As of January 1979, all elderly developments had a mean occupancy of 91.8 percent, while 
the family developments sustained a mean rate of only 78 percent. By using these figures, the Housing Authority occupancy rate is 78 percent instead of 81 percent. This would place the overall Housing Authority family projects approximately 13 percent above the 65 percent rate for Bromley Heath.

From May 1974 to February 1979, the occupancy rates at Bromley Heath dropped from 79.3 percent to 63.0 percent, a decrease of 16.3 percent (see Table 1). The overall Boston Housing Authority developments (excluding Bromley Heath) occupancy declined from 93.0 percent to 81 percent, a decrease of 12.0 percent. Once again, the figures for the Housing Authority include data for the elderly developments. If the elderly developments were factored out, it would show a greater decrease. The difference between the two statistics is 4.3 percent (see Table 2). However, in relation to the Housing Authority as a whole it cannot be inferred that Bromley Heath is experiencing greater occupancy problems.

Since efforts are being made by the Housing Authority to bring all occupied units up to housing code standards, and Bromley Heath is following a policy of producing quality units, the difference in occupancy rates cannot be used to draw significant conclusions. It can be stated, however, that Bromley Heath, in terms of occupancy, has not deviated significantly from the figures for the Housing Authority. 
Table 2

Percent Changes in Occupancy Rates and

Cumulative Absolute Changes in Number

of Units Occupied

\begin{tabular}{|c|c|c|c|c|c|c|}
\hline \multirow{2}{*}{$\begin{array}{l}\text { May } \\
1974 \\
\text { Eo }\end{array}$} & \multicolumn{3}{|c|}{ Percent Changes } & \multicolumn{3}{|c|}{ Cumulative Absolute Changes } \\
\hline & Bromley & Boston & $\begin{array}{c}\text { Columbia } \\
\text { Pt. }\end{array}$ & Bromley & Boston & $\begin{array}{c}\text { Columbia } \\
\text { Pt. }\end{array}$ \\
\hline Oct. 74 & $-1 \cdot 3 \%$ & -2.5 용 & $-1.0 \%$ & -11 & +166 & -7 \\
\hline May 75 & $-3 \cdot 3$ & $-1 \cdot 0$ & $-12 \cdot 0$ & -35 & +247 & -160 \\
\hline oct. 75 & -3.5 & $-4 \cdot 5$ & -20.0 & $-I I$ & -135 & -267 \\
\hline Jan. 76 & -3.8 & -5.4 & -27.0 & -40 & -254 & -304 \\
\hline May 77 & -9.9 & N.A. & -6.0 & -111 & N.A. & -475 \\
\hline Oct. 77 & -11.0 & N. A. & -10.0 & -141 & N. A. & -501 \\
\hline May 78 & $-12 \cdot 8$ & -9.0 & -7.0 & -164 & -887 & -542 \\
\hline oct. 78 & -16.0 & -8.3 & -13.0 & -200 & -674 & -569 \\
\hline Feb. 79 & -16.3 & -12.0 & -12.5 & -181 & $-1,258$ & -569 \\
\hline
\end{tabular}

Source: Boston, Massachusetts, Boston Housing Authority,

Data from Minority Occupancy Report (1979).

Occupancy rates for the Columbia Point development, which is located in Dorchester across the bay from the University of Massachusetts (see Appendix A, Table 7), cannot be directly compared to the rates for Bromley Heath. Many other factors would be required to be calculated into a multiple regression analysis before any inferences could be drawn. It is possible that some of these variables cannot be calculated in any case. 
Since Columbia Point had originally been selected for the Office of Economic Opportunity grant in 1968, it might be appropriate to determine what has transpired there in 11 years. It should hot be concluded, however, that tenant management would have prevented its demise, although it is not to say it may not have. From May 1974 to February 1979 the occupancy rate at Columbia Point declined from 70.0 percent to 57.5 percent, a decrease of 12.5 percent. A closer look reveals a much more striking statistic. The total number of units available declined from 1370 to 670 (3850 occupied) between May 1974 and February 1979. That means that less than 50 percent of the original development is not secured (boarded up). On the other hand, in May 1974, Bromley Heath had 1150 total units (912 occupied), and in February 1979 had 1130 (731 occupied). It should also be noted that some of these units represented converted offices for the TMC.

The effectiveness of tenant management at Bromley Heath cannot be measured solely by how the occupancy rates increased or decreased due to several factors:

1. A triage policy (quality not quantity)

2. Overall operating and capital improvement budget limitations

3. Inherent limitations on the reliability of data submitted on the Minority Occupancy Report, due to the fact that the figures were sent in by the individual development managers without a mechanism established by the BHA to determine reliability of the data. 
Before the occupancy rates at Bromley Heath can be increased, several additional difficulties must be overcome. These have been previously mentioned in the Bromley Heath Urban Initiative (UI) proposal. The first problem is that there are many one-bedroom units in the Heath St, development. They are at the present time in unmarketable condition. Given the present standards for admission, only elderly would be eligible for tenancy. Since there are families already residing in the building, it would not be possible to place elderly people there. In addition, security for the elderly could not be provided in these scattered locations or in the totally elderly developments. The TMC is in the process of eliminating many of these one-bedroom units through what is referred to as a "breakthrough method," which would combine several of these one-bedroom units. Bromley has a waiting list for units, with the majority of these households seeking three or four-bedroom units.

The second situation concerns one building at Bromley Heath which was constructed with fourteen, four-bedroom units and fourteen, one-bedroom units. All the four-bedroom units are occupied by what is considered a stable population. The building itself is considered a good one, although eleven units are vacant. Again, due to the high concentration of children, TMC cannot house the elderly in this building. The TMC has considered two 
alternatives. One, is to combine all the one-bedrooms with the four-bedrooms; and the second, is to rent the one-bedrooms to "elderly oriented" tenants.

A third problem is that of the pattern of vacancies which exists at Bromley. The UI proposal stated that, "The greater the distance between community space and the apartments, the more likely these apartments are to become vacant." ${ }^{I}$ TMC has considered placing laundromats in some of these areas which would provide a focal meeting point in an attempt to stabilize the area. The fourth problem is that of first and seventh floor occupancy. Buildings which have low foundations (most are high), make first floor living undesirable (due to security problems). In order to rectify this situation, the UI proposal suggested installing better screens and putting laundromats in several of the units. Seventh floor apartments are difficult to market because of the method in which Bromley's elevators operate. They stop on the first, third and sixth floors only. This leaves those tenants on the seventh floor isolated. TMC is considering the possibility of retrofitting the elevators to stop on all floors, particularly the seventh floor.

We can see that the vacancy problem at Bromley is related not only to a lack of modernization and capital improvement funds, but also to security issues, common areas for gathering, density, and management issues. Decisions concerning improvements must be made in a 
comprehensive manner. The infusion of tenant management in and of itself, cannot be thought of as an immediate solution. The problems mentioned are those which existed well before the arrival of the TMC. The construction issues were, of course, not forseen in the 1940's and 1950's when the relation of physical planning to social issues was not given much consideration. Here, we have a good example of a failure to integrate the two sides of the coin. However, the fact these problems have been recognized, addressed and attempts are being made to acquire funding, indicate progress in the right direction on the part of TMC. Until adequate funding is forthcoming, the policy of producing quality units, not quantity units, will probably be the direction which the TMC will aim.

\section{Security and Crime at Bromley Heath}

There are several areas which this study has

focused upon. The first area which has been examined is the occurrences of crime against property (see Table 3 and Figure 3). This illustrates the various property crimes which have been reported during the period from January 1973 to August 1978 in the area of Bromley Heath. The largest single category, in terms of absolute numbers, is auto theft, with 81 . This is followed by larceny, with 76. The total number of crimes against property dropped by over 50 percent between August 1974 and August 1978, with the greatest decreases taking place in larceny 
and auto theft. The incidents of breaking and entering and vandalism, during this same period, have remained steady and well below the larceny and auto theft figures.

Table 3

Reported Crimes Against Property and Persons for the Bromley Heath Report Area, 1973-1978

\begin{tabular}{|c|c|c|c|c|c|c|c|c|c|c|c|c|}
\hline \multirow[t]{2}{*}{ Date } & \multicolumn{5}{|c|}{ Crimes Against Persons } & \multicolumn{7}{|c|}{ Crimes Against Property } \\
\hline & 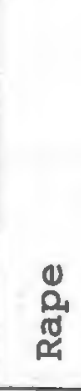 & 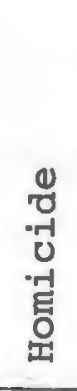 & 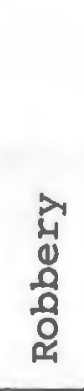 & 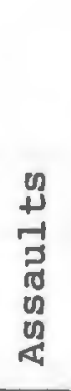 & 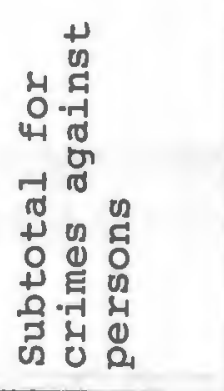 & 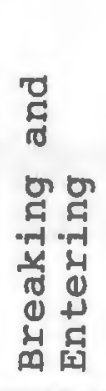 & 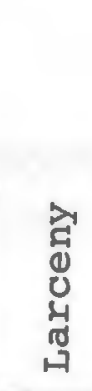 & 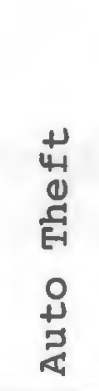 & 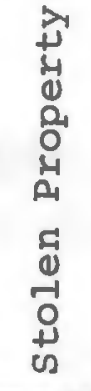 & 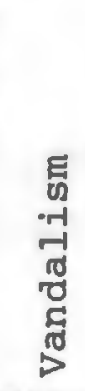 & 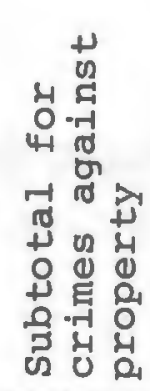 & 足 \\
\hline Jan. 73 & 0 & 0 & 0 & 0 & 0 & na & na & na & na & na & na & 0 \\
\hline May 73 & 0 & 0 & 0 & 0 & 0 & na & na & na & na & na & na & 0 \\
\hline Jan. 74 & 0 & 0 & 7 & 1 & 8 & 5 & 2 & 6 & 0 & 3 & 16 & 24 \\
\hline May 74 & 0 & 0 & 10 & 5 & 15 & 4 & 11 & 6 & 0 & 1 & 22 & 37 \\
\hline Aug. 74 & 0 & 0 & 10 & 7 & 17 & 5 & 16 & 11 & 0 & 1 & 33 & 50 \\
\hline Jan. 75 & 1 & 0 & 19 & 2 & 22 & 2 & 6 & 3 & 0 & 2 & 13 & 35 \\
\hline May 75 & 0 & 0 & 20 & 9 & 29 & 2 & 11 & 9 & 0 & 6 & 28 & 57 \\
\hline Jan. 76 & 0 & 0 & 3 & 2 & 5 & 3 & 4 & 8 & 0 & 1 & 16 & 21 \\
\hline May 76 & 0 & 0 & 3 & 4 & 7 & 1 & 4 & 5 & 0 & 2 & 12 & 19 \\
\hline Aug $\cdot 76$ & 0 & 0 & 2 & 3 & 5 & 1 & 3 & 5 & 1 & 1 & 11 & 16 \\
\hline Jan. 77 & 0 & 0 & 2 & 7 & 9 & 3 & 4 & 4 & 0 & 0 & 11 & 20 \\
\hline May 77 & 0 & 0 & 4 & 6 & 10 & 6 & 1 & 4 & 0 & 3 & 14 & 24 \\
\hline Aug. 77 & 0 & 0 & 3 & 7 & 10 & 7 & 6 & 2 & 0 & 1 & 16 & 26 \\
\hline Jan. 78 & 1 & 0 & 0 & 10 & 11 & 2 & 0 & 4 & 0 & 3 & 9 & 20 \\
\hline May 78 & 0 & 0 & 4 & 4 & 8 & 8 & 5 & 6 & 1 & 2 & 22 & 30 \\
\hline Aug. 78 & 0 & 0 & 1 & 8 & 9 & 4 & 3 & 8 & 0 & 1 & 16 & 25 \\
\hline TOTALS & 2 & 0 & 88 & 75 & 165 & 53 & 76 & 81 & 2 & 27 & 239 & 404 \\
\hline
\end{tabular}

Source: Boston, Massachusetts, Boston Police Department Crime Reports for the Boston Housing Authority 
Figure 4: Selected Reported Crimes Against Property in the Bromley Heath and
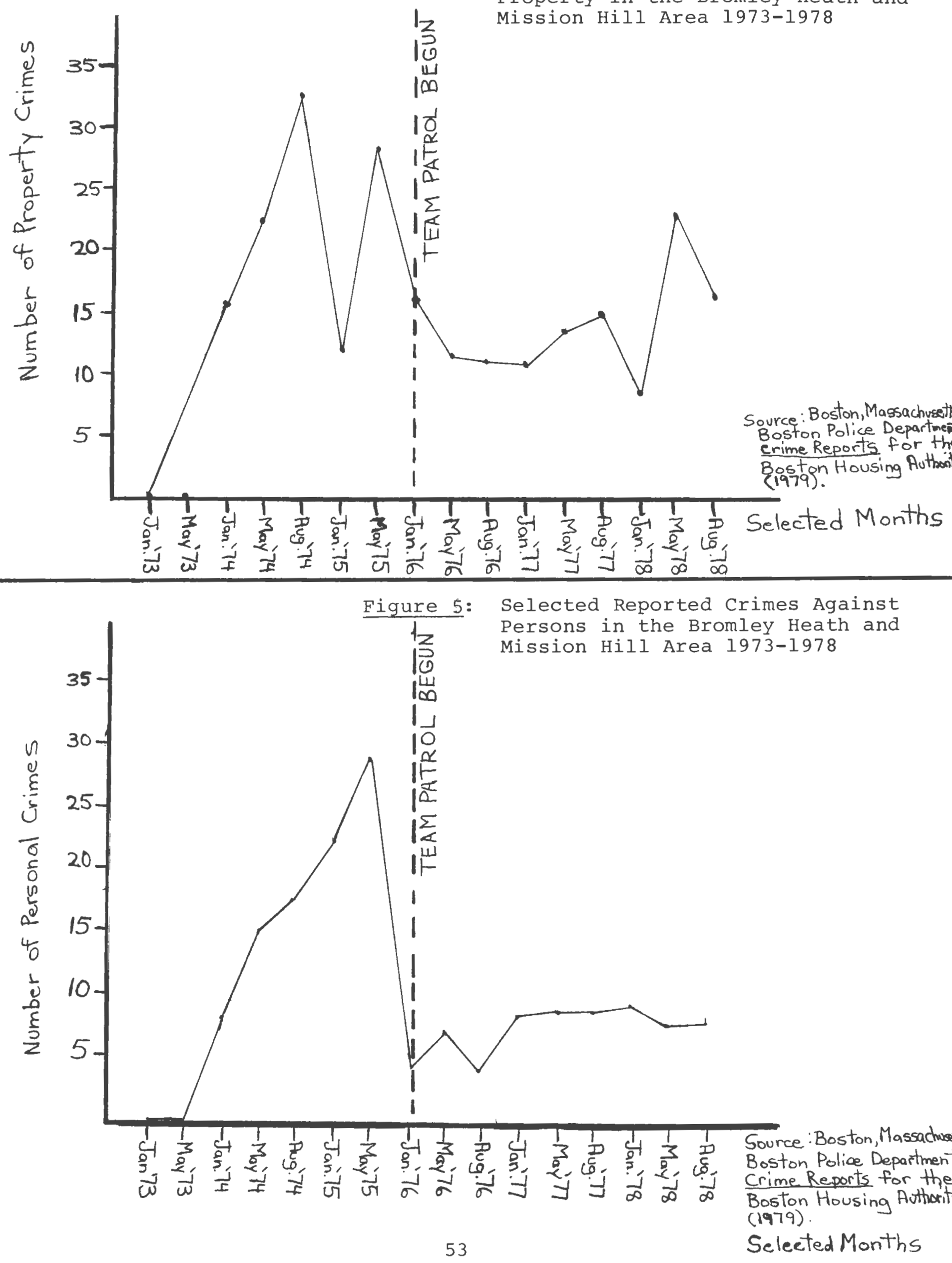
The graphical representation (Figure 3 ) of this data shows a large decline from May 1975 to January 1976. Part of this decrease is due to seasonal change. However, not all of this can be explained by this factor alone. If the May months are plotted alone, there is still somewhat of a decline in the number of crimes against property after the beginning of 1976.

Crimes reported against persons were concentrated in incidents of robbery and assaults (see Table 3 and Figure 4). These crimes reached a peak of 29 in May 1975, and dropped to eight in May 1978. The decreases in crimes against persons were far more dramatic than crimes against property for the same period. Part of the reason for this change is due to the Team Patrol Unit of the Boston Police Department, and the Bromley Heath Community Security Patrol.

In 1975, Bromley Heath began its Community Security Patrol and the following year, the police instituted the Team Patrol program in the Mission Hill District which includes Bromley. Bromley Heath is assigned one patrol car.

The Team Patrol Unit begun in 1976, has greatly decreased the number of crimes in the area. Statistics were collected by the Police Department Consultant for the years 1975-1978 in order to determine how effective the new Team Patrol concept had been (see Figures 9 and 10 in Appendix $B$ and Table 4). The number of auto thefts dropped from 63 in 1975, to 2 in 1978, while robbery, in 
Table 4

Selected Crime Statistics - Team Patrol Unit for Police District Two Boston - 1975-1978

\begin{tabular}{|c|c|c|c|c|c|c|c|c|}
\hline \multirow[t]{2}{*}{ YEAR } & \multicolumn{2}{|c|}{ AUTO THEFT } & \multicolumn{2}{|c|}{ LARCENY } & \multicolumn{2}{|c|}{ AGGRAVATED ASSAULT } & \multicolumn{2}{|c|}{ ROBBERY } \\
\hline & Bromley & $\begin{array}{c}\text { Mission } \\
\mathrm{Hill} \\
\end{array}$ & Bromley & $\begin{array}{c}\text { Mission } \\
\text { Hill }\end{array}$ & Bromley & $\begin{array}{c}\text { Mission } \\
\text { Hill } \\
\end{array}$ & Bromley & $\begin{array}{c}\text { Mission } \\
\text { Hill } \\
\end{array}$ \\
\hline 1975 & 63 & 93 & 49 & 52 & 37 & 50 & 132 & 73 \\
\hline 1976 & 7 & 17 & 15 & 37 & 2 & 5 & 8 & 11 \\
\hline 1977 & 0 & 23 & 11 & 10 & 0 & 3 & 3 & 9 \\
\hline 1978 & 2 & 22 & 3 & 16 & 0 & 1 & 3 & 3 \\
\hline \multirow[t]{3}{*}{ TOTALS } & 72 & 155 & 78 & 135 & 39 & 59 & 149 & 96 \\
\hline & \multicolumn{2}{|c|}{ BURGLARY } & \multicolumn{2}{|c|}{$\overline{R A P E}$} & \multicolumn{2}{|c|}{ HOMICIDE } & & \\
\hline & Bromley & \begin{tabular}{|c} 
Mission \\
Hill \\
\end{tabular} & Bromley & $\begin{array}{c}\text { Mission } \\
\text { Hill } \\
\end{array}$ & Bromley & $\begin{array}{c}\text { Mission } \\
\text { Hill }\end{array}$ & & \\
\hline 1975 & 61 & 48 & 3 & 1 & 2 & 3 & & \\
\hline 1976 & 3 & 6 & 0 & 0 & 0 & 0 & & \\
\hline 1977 & 0 & 4 & 0 & 0 & 0 & 0 & & \\
\hline 1978 & 1 & 0 & 0 & 0 & 0 & $\underline{0}$ & & \\
\hline TOTALS & 65 & 58 & 3 & 1 & 2 & 3 & & \\
\hline
\end{tabular}


The Bromley Heath Community Security Patrol which began in 1975 with funding from CETA, was comprised mainly of foot patrolmen. According to the management at Bromley, it is important to supplement the Team Patrol Unit because patrol cars are not able to enter many areas of the development. In addition, foot patrols are more effective in the high rise buildings at Bromley Heath. According to Sgt. Arthur Leats, of the Boston Police Department, District Two, the Community Patrol has been effective in deterring crimes in the project area. In his judgment, the Tenant Community Patrol has also provided a sense of security to the tenants, especially the elderly residents, through the visibility factor. ${ }^{2}$ Ms. Mildred Hailey, the Executive Director of the TMC at Bromley Heath, has commented that an important aspect of the patrols' effectiveness is that it has created an informal mechanism for dealing with vandalism and mischievous behavior because its members are Bromley Heath residents who are known to the tenants, and who know first hand many of the problems in the development. 3

A good portion of this mischievousness and vandalism is related to those under 21 , who comprise 75 percent of the tenants.

There are some who argue that having tenants on a community patrol does not deter crime, and is counterproductive. Because the patrolmen are from the community, they may be less inclined to "blow the whistle" on friends 
or neighbors involved in criminal activity. This may be so at times, but habitual laxness in performance of duties would eventually be noticed by superiors who would replace them with more competant patrol persons. The Team Patrol Unit which was mentioned previously, has also been able to reduce the incidents of crime in the Mission Hill area. Table 4 and Appendix B Figure 10 shows that after the introduction of the Team Patrol the reported cases of burglary fell from 48 in 1975 to zero in 1978 in Mission Hill, and in Bromley Heath from 61 in 1975 to 1 in 1978. Although the time frame is short, it does indicate a significant change, much of which is due to the Team Patrol Unit and the Bromley Heath Community Security Patrol. It should also be noted many crimes are not reported, and the data shown here would not reflect these unreported offenses. Rape is one such crime which has a low reporting percentage, and the data which indicates three rapes in four years is considered an extremely conservative figure. The actual number is probably higher.

In an interview with Mr. Ellis Ash, a former Director of the Boston Housing Authority and the present consultant to the Bromley Heath TMC, he discussed the effectiveness of the community security Patrol in an emergency situation. 
Several years ago there was a large abandoned factory adjacent to the Bromley Heath development which had allegedly been set on fire by arsonists. Although the fire did not spread to the housing project, the intense heat from the flames shattered windows in the building housing elderly residents, which was closest to the engulfed factory. Before the police or firefighters responded to the emergency, the community Security Patrol had managed to evacuate all the residents and bring them to the community center. A member of the Red Cross later commented to several members of the TMC, that the Patrol's quick action was very professional.

As to whether or not the efforts of tenant management in the area of security have been effective, may not be quantitatively measurable. But from some indications, it appears that through a combined effort of the Community Security Patrol and the Team Police Patrol Units, the incidents of crime have been substantially reduced. Compared to the 1970 report issued by TransUrban East which stated the residents of Bromley were afraid to leave their apartments for fear of attack, significant achievements have indeed been made.

TMC Employment of Residents as a Measure of Achievement

Bromley Heath is a predominantly black and Spanish speaking inner city housing development. The unemployment rate for these two groups is extremely high, approximately 
twice that of whites. Many residents of public housing who do find work are usually relegated to becoming part of a secondary labor market. The secondary labor market consists of jobs with low wages, few benefits, poor working conditions and a high turnover rate. The problem of unemployment is even greater for black youths. In an effort to deal with this situation, Action for Boston Community Development ( $A B C D$ ) sponsors a yearly federal Summer Job Program for low income youths between the ages of 14 to 21. The program is designed to provide work experience and training to economically disadvantaged youths. The program has been in operation for fourteen years, and has employed over 120,000 young people during that period in Boston. 5 Although $A B C D$ is not part of the TMC organization, two of its locations are within walking distance of Bromley. The TMC also acts as a referral agency for $A B C D$. More directly related to the TMC are the people who have been employed in management and staff positions. The executive director, assistant director and the staff person in charge of tenant selection are residents of Bromley. There are thirteen skilled craftsmen employed by the TMC, seven of whom are residents, as well. The remaining thirty or so residents are employed by the TMC as general maintenance workers. Table 5 shows the breakdown by year for four years for the number of employees of the TMC. 
Table 5

Employment of Residents at Bromley Heath Through

The Tenant Management Corproation 1975-1978

\begin{tabular}{l|c|c|c}
\hline Year & $\begin{array}{c}\text { Total } \\
\text { Employees }\end{array}$ & $\begin{array}{c}\text { Residents of } \\
\text { Bromley }\end{array}$ & $\begin{array}{c}\text { Percent Residents/ } \\
\text { Total Employee }\end{array}$ \\
\hline 1975 & 60 & 40 & $67 \%$ \\
1976 & 58 & 45 & $78 \%$ \\
1977 & 59 & 40 & $68 \%$ \\
1978 & 58 & 40 & $69 \%$ \\
\hline
\end{tabular}

Source: Bromley Heath Tenant Management Corporation, Accounting Dept., (1979).

Another source of employment for residents is the Community Security Patrol. Although the patrol has not been in operation since October 1978 (due to having exhausted CETA funds), it is expected that the patrol will begin operating in the near future. Recently, the TMC submitted a CDBG application requesting funding in order to reactivate its security patrol. Additionally, funding was requested for site improvement at the development. As of April 1979, the mayor's office had recommended $\$ 80,000$ for the security patrol, and $\$ 20,000$ for site improvement. The major priority in site improvement is for fencing, particularly for enclosing residents' gardens.

If the Boston City Council approves the recommendation, it would enable the TMC to hire six patrol 
persons, a director and a dispatcher. All of the employees in the patrol would be Bromley Heath residents.

In August 1978, the TMC submitted an Urban

Initiative proposal for funding. This proposal included a section dealing with the community patrol and an expansion of their duties which would be to:

1. Guard apartments under renovation, or between renovations and the time when they are rented.

2. Keep constant watch over all activities surrounding the elderly development.

3. Provide escort services for vendors, as requested.

4. Maintain general watch over development activities, and prevent or ${ }_{6}$ report crimes to police, as appropriate.

The CDBG proposal indicated that a new position, that of a dispatcher, would be created. The dispatcher would be responsible for transmitting calls from tenants to the patrolman on the street by way of two-way radio, and for relaying messages from the community patrolmen to outside city support agencies such as the fire and police departments. This system would greatly enhance the patrol's effectiveness, and reduce police response time to the development.

TMC has been able to provide some employment opportunities for residents of Bromley Heath. Although the actual number of people hired is not great, it has shown residents and others that a greatly under-utilized resource such as the tenants, can be harnassed and used to benefit the whole development. Tenants' involvement 
conveys a greater sense of community pride, and a feeling that this is their "home". The TMC management believes that including residents in jobs in the development encourages other tenants to take equal interest in not just the project, but in their community and home as well. This is an essential difference, since residents who feel a kinship in their community will be motivated to be concerned about looking after its well being. Involving tenants is extremely important if the tenant-management concept is to be successful.

\section{Maintenance as an Indicator}

Although maintenance has been used as an indicator of change in this paper, no quantitative data was obtained. However, after discussion with several staff members of the Bromley Heath TMC and staff members of the Housing Authority, it appears the litter problem has been greatly abated. There is a striking difference between the trash problem at the Mission Hill development and the relative lack of such deficiency at Bromley Heath. Before the TMC began operating at Bromley, burned out auto wrecks were a common sight. Today, tenants' gardens have replaced such eye sores.

As was discussed in Chapter II, the maintenance procedure which was established provided for specific steps to be followed once a unit became vacant. The ability to quickly ready a vacated unit for re-rental is essential because a unit that is left unattended for an 
extended period eventually becomes prey to vandals and squatters. This was discussed in Chapter 1 in the section on the income squeeze cycle.

The establishment of a TMC maintenance crew has enabled approximately 30 residents to obtain employment on the premises. 
ENDNOTES

Chapter III

1. Bromley Heath Tenant Management "Targeted Rehabilitation Proposal for Bromley Heath Development" (Boston, 10 August 1978), p. 9.

2. Interview with Sgt. Arthur Leats, Boston Police Department, District 2, Boston, Massachusetts, 11 April 1979.

3. Interview with Mildred Hailey, Executive Director, Bromley Heath Tenant Management Corporation, Boston, Massachusetts, 2 February 1979.

4. Interview with Ellis Ash, former Head Administrator of Boston Housing Authority, present consultant to Bromley Heath TMC, Boston, Massachusetts, 16 February 1979.

5. Jamaica Plain Area Planning Action Council. "Registration for $A B C D$ 's summer jobs for Young Opens," Community Forum (March 1979): 3.

6. Bromley Heath TMC Targeted Rehabilitation Proposal for Bromley Heath Development, p. 29. 
IV. AN ALTERNATIVE MODEL OF TENANT MANAGEMENT

Another method of utilizing the concept of tenant management is being carried out in St. Louis, Missouri. The birth of the tenant management organization stemmed from a rent strike in 1969. This section will discuss the various components of this type of tenant management, as well as offer an analysis of National Tenant Management Demonstration Program which is being funded by The Department of Housing and Urban Development. This demonstration project is presently in operation. In this section there will also be a qualitative evaluation of this model of tenant management.

As mentioned earlier, most housing authorities have financial difficulties because operating costs have escalated much more rapidly than the available rental incomes. In an attempt to equate this problem, the St. Louis Housing Authority decided in October 1968 to institute a flat rent fee for its units. The intent of this new policy was to attract moderate income working families, as well as encourage employed tenants to remain in public housing. A problem arose for a large portion of residents who were living on fixed incomes. Welfare benefits had not increased comparably to inflation. Many residents found themselves in worse financial conditions 
than ever before. During "1968-69 the level of welfare benefits provided by the State of Missouri to an AFDC family of four was $\$ 124$ a month, which placed Missouri forty-fourth in the United States." ${ }^{1}$

The tenants of public housing became outraged at this flat rent rate, and this finally lead to a rent strike throughout the housing projects. The tenants demanded that a maximum rent schedule of 25 percent of income be instituted in place of the flat rent rate. The concept of a 25 percent maximum rent schedule later became the Brooke Amendment. The strike lasted throughout most of 1969. It was evident from the demands of the striking renters that they wanted not just to have an advisory role in Authority matters, but also substantial control over decisions affecting tenants in the Authority. When the strike was settled, it was agreed that:

1. No tenant would pay more than 25 percent of his/her income toward rent.

2. Delinquent rent would be repaid within two years of the settlement date.

3. The Authority would develop a modernization program with full participation of the residents and,

4. to support a program of 'tenant management'. . .2 The Civil Alliance for Housing ( $\mathrm{CAH}$ ); a group of clergy, business interests and others, was instrumental in aiding the Authority and the Tenant Affairs Board (TAB) coordinate plans for the TM program. CAH paid the salaries of TAB members for several years until 1972. In 1973, the Ford Foundation agreed to provide an initial $\$ 130,000$ grant 
to form two tenant management corporations; one in the Carr Square Village, and the other in the Darst Apartments. The Tenant Advisory Board salaries were paid by the St. Louis Housing Authority through operating expenses with permission from HUD. In 1974, a second grant from the Ford Foundation permitted the establishment of tenant management in the Webbe and Clinton Peabody apartments. Richard Baron was responsible for laying the groundwork for the tenant management model in St. Louis. Mr. Baron had borrowed much of the elements of tenant management which had been in operating at Bromley Heath. The following are the principle elements involved in the st. Louis TMC:

1. A Board of Directors for each development community.

2. Administrative structure and responsibility of the resident management staff.

3. Training and technical assistance provided to the TMC.

4. 'Soft Management' program - this includes youth and social service programs which would be administrated by the TMC.

The St. Louis TMC's were very much interested in providing services to the developments which had previously been provided by other than management. Social services were provided by separate agencies such as the Community Action agency. In an attempt to establish more of a community environment, the TMC would be the "umbrella" under which management and social services would be located. 


\section{Legal and Administrative Structure}

Each TMC has a Board of Directors which consists of five members elected by the residents every three years, and who serve without salary. The resident managers and chairpersons of each TMC serve on the Tenant Affairs Board. The TAB represents the tenants in major decisionmaking actions in the conventional developments.

The Board of Directors and its staff are responsible for establishing rules and regulations. These edicts had previously been adopted by tenant associations or the Authority, but not enforced in actuality. Violations of these rules are referred to the Board, and may be heard by the Authority, if it is so requested. The Board is also responsible for notifying residents about job openings. The resident managers of each development are given the task of interviewing and hiring all TMC personnel at their respective developments.

The Board holds meetings to discuss major policy decisions with the residents and staff members. More frequent meetings are held between the staff and the Board to deal with day-to-day matters such as rent collection, maintenance and other TMC responsibilities.

\section{Administrative Staff}

The staff structure of the TMC's is similar to that of the St. Louis Housing Authority, except that the TMC's have building and lane managers. The major staff positions in the TMC's are resident manager, assistant 
resident manager, building or lane manager, management aid, clerk typists, and social director.

Both the resident and assistant resident managers in each development assume total management responsibility. Some of these duties include apartment leasing, rent schedule determination, annual reviews, eviction process security and social service programs. Both managers are required to reside in the development in which they work. The philosophy being, that since they live in the development, they will tend to take more of an interest in decisions concerning the development.

The responsibility for tenant screening and selection is endowed to the TMC at each site. This has eliminated from the Housing Authority the responsibility for this function. However, the Authority must still monitor the process for compliance with HUD and Housing Authority guidelines. The procedure for tenant selection is similar to that utilized at Bromley Heath. In both cases, decentralization of tenant selection has been found to be very effective in terms of marketing and in the reduction of the necessary processing time. One aspect of the St. Louis TMC which is unique is that of the Building/Lane Managers. They are generally responsible for performing certain functions within an area composed of 125 units. The Building/Lane Managers are the informational link between the TMC and the residents, and deal directly with rent delinquency, tenant 
orientation to the TMC and distribution of notices regarding management problems. These managers are responsible for accommodating residents with grievances, and for overseeing custodial activities. The custodians are teamed with a building or lane manager, and are assigned a daily work schedule which is approved by this manager.

An important function of a building manager is to alert the TMC when a unit has become vacant. A regular procedure for readying a vacated apartment for new tenants is essential in order to minimize vandalism. As mentioned in Chapter III, the longer the vacant period, the greater the potential for damage and theft of appliances. At times, the building/lane managers will substitute as a clerk-typists or maintenance persons. Mr. Baron has suggested that the varied activities provide the managers with opportunity for the TMC to promote residents to positions held by non-residents. This flexibility in changing roles also incurs payroll savings for the TMC. Each TMC has a maintenance supervisor and four to six maintenance persons, all of whom are union members. The supervisor is responsible for both maintenance and custodial activities, and reports directly to the TMC resident manager or contract manager. The maintenance people serve as "generalists" and perform a variety of services within each development. It isn't clear whether there is a graded pay scale for the levels of skills required. 
The St. Louis TMC's participate in a centralized purchasing system with the Housing Authority. Baron states that this system permits the TMC's to take advantage of the Authority's experience and avoids the cost of hiring a staff person to perform this function. The Authority charges the individual TMC by prorating the cost of the purchasing service against the development buaget for its services. 4

An integral part of the TMC staff is the security force. The security supervisor of each development reports directly to the resident manager or other private manager. Each manager and supervisor is responsible for determining the patrol schedule for that development. The security guards, who are hired by the TMC, are given a six week training course. As of 1976, thirty-one percent of the security patrol (Authority-wide) are residents, and forty percent are female. 5

According to preliminary evaluation conducted by Richard Baron, the incidence of vandalism in the TMC areas had significantly decreased from 1973 to 1975. The organizing and program efforts of the TMC's appear to be making a positive impact, according to Baron's analysis. 6 However, neither police statistics nor qualitative information from residents were provided, which would offer an indication of the extent of this change. In addition to the traditional management functions mentioned thus far, the TMC's in St. Louis deal with 
what Baron refers to as the "soft management" programs. In combining both traditional management and social service functions, there is an attempt to create more of a community atmosphere. The TMC's are also involved in bringing both educational and employment opportunities to the TMC communities, areas which were traditionally neglected in the past. There is an attempt to harness a great deal of human resources which heretofor has been greatly under-utilized. Further bringing management into greater contact with the social needs of the residents, creates the potential for a greater understanding of the problems afflicted by some families.

Although placing the social service management function in the organizational structure can produce beneficial results, it is not necessarily the most effective or only position for social services. Later in this chapter there will be a discussion of the stella Wright Development in Newark, New Jersey, which is modelled after the TMC experience in St. Louis. This development is an example of where the functions of "hard" and "soft" management are combined, yet do not appear to create a substantially better understanding, or greater social awareness on the part of management. The Bromley Heath TMC serves mainly as a referral to the social service agencies in the area (see Chapter II). Although it has the capacity to administer social service programs, this function is carried out by a separate 
social service organization. The separation of these functions does not seem to effect the ability of either the TMC or the social service agency to "deliver," according to several staff members at Bromley Heath. In 1974, the TMC's in St. Louis were able to obtain, from the Ford Foundation, funding for the hiring of a social director to develop social and recreational activities. Examples of these activities included Boy and Girl Scout troops, field trips, and publication of a community newspaper. In 1975, the TMC's, together with the Authority, and the office of Manpower of the City of St. Louis, had undertaken an employment demonstration program. This was made possible with funding from the Manpower Demonstration Research Corporation and HUD, through the Target Projects Program (TPP). The purpose of the program was to develop strategies to employ the AFDC population in TMC developments.

This program has provided training in food service preparation, visiting nurses/nurse practitioning, clericalcomputer entry and other areas which indicate market demand. It is an attempt to deal with ineffective employment programs which have not permitted many trainees to secure jobs in the primary labor market. The TMC's had made arrangements with the Missouri Division of Family Services to provide day care, infant care, homemaker and food preparation services for the residents, as well as combine the HUD, Labor and HEW programs. The tenant management 
program has, in itself, provided a number of job opportunities in real estate management and security. The four TMC developments in St. Louis indicated the following demographic characteristics in 1973:

1. $70 \%$ of population under 21 .

2. $65 \%$ of families have single head of household.

3. $70 \%$ of families are on fixed income.

4. Unemployment ranges from 55\% in Carr Square to $80 \%$ in Webbe.

According to Baron, despite these problems and since the inception of tenant management, rent collection increased greatly in all the developments. There was also a decrease in vacancies which was accomplished by efforts to rent vacant, one and two-bedroom units and renovate vandalized units. However, these positive steps had also contributed to tenants being evicted for non payment of rent and so-called "anti-social behavior." In Baron's discussion of these evictions, there is no interpretation of anti-social behavior. Is there a caseby-case approach to the problem of non payment of rent? Are there certain family problems at this time which must be dealt with? Is there a rent schedule which could be established to pay back rent? None of these issues are brought forth in Baron's discussion, although they had originally envisioned combining the "hard" and "soft" managements to create an environment which would hopefully lead to a better understanding of the social problems existing in public housing. There does not seem to be a corollary here between goals and the methods for achieving 
these goals.

The following changes have occurred since the inception of tenant management:

$\begin{array}{ll}\text { Carr Square } & \text { - Vacancies decreased from } 45 \text { to } 5 \\ \text { Darst Apart. } & \text { - Vacancies decreased from } 280 \text { to } 185 \\ \text { Peabody } & \text { - Vacancies decreased from } 46 \text { to } 27 \\ \text { Webbe } & \text { - Vacancies decreased from } 140 \text { to } 70\end{array}$

In the four developments, the number of working heads of households selected as tenants increased, and correspondingly did per unit/month rental income. The following represents the changes in rental income in the four developments from 1973-1975:

$\begin{array}{lr}\text { Carr Square } & \text { Rental income increased from } \\ & \$ 42.26 \text { to } \$ 51.48 \\ \text { Darst Apart. } & \text { Rental income increased from } \\ & \$ 40.48 \text { to } \$ 46.35 \\ \text { Peabody } & - \text { Rental income increased from } \\ & \$ 46.27 \text { to } \$ 51.487 \\ \text { Webbe } & -\$ 43.34 \text { to } \$ 44.86\end{array}$

A report submitted by the Center for Urban Programs of St. Louis University, stated that in both the Darst and Carr Square developments, the trash and litter problems had been curtailed, and vandalism had been greatly reduced. ${ }^{8}$ According to the indicators and methodology used by Baron, and the report issued by the St. Louis University research center, tenant management in st. Louis has proven to be a success in spite of the short period (1973-1975) of its existence.

It should be recognized that St. Louis was fortunate in its ability to obtain grants from various federal agencies and the Ford Foundation. Without this funding, tenant management would not have been feasible 
because the financial capacity of the Housing Authority would not have been able to sustain its implementation. Although it wasn't explicitly stated, the incomes of those tenants moving into the TMC developments were generally higher than those of the existing tenants. This is evident from the rental income levels charged to the new tenants. An important issue which must be raised here is: Is the problem of housing lower income households being "solved" by their eviction and replacement by higher income tenants? The question is, who is the client group which should be served? This will be discussed in further detail in the following section.

The National Demonstration Program for Tenant Management

The St. Louis experiment with tenant managed public housing encouraged the Ford Foundation and HUD to sponsor a demonstration program in 1975 in several cities across the country. There are six TMC demonstration development sites which are presently participating in the program. These six sites comprise a total of 4,788 apartments which provide housing for approximately 19,000 low income persons. "Most of the projects are low rise, walk up buildings; most have heavy concentrations of female-headed and minority group families; and there is a substantial welfare dependency." 9 HUD would prefer to see the cycle of welfare dependency in public housing broken, and the creation of a more cohesive community in 
conventional public housing. Tenant management may provide part of the answer to what HUD is seeking.

$$
\text { St. Louis was used as the model for setting up }
$$

the demonstration program. This being the case, the management functions at all of the demonstration sites are similar to those in effect at the St. Louis TMC developments. The objectives of the demonstration program are, as well, similar to those of the TMC in St. Louis. They are as follows:

1. Improve the operating performance in vacancies, rent collection, project income and maintenance.

2. Reduce crime and vandalism.

3. Improve community spirit and public housing image in the broader community.

4. Provide employment opportunities for the residents of the development. 10

Since the demonstration program is relatively new, obtaining sufficient information for an evaluation was not wholly possible. However, one development, the Iroquois Homes Project in Louisville, Kentucky, was able to furnish some information. A brief discussion of this development follows.

\section{Iroguois Homes, Louisville, Kentucky}

Constructed in 1952, this development is comprised of 72 buildings ( 853 units) on a 42 acre site. One major factor which distinguishes it from all others in the demonstration program is that $75 \%$ of its residents are white, and 25 응 are black.

The housing authority director commented, in the 
nominating phase of the program, that Iroquois was, "one of the best and most desirable of all the public housing in the city."Il The intent of the director was to eventually establish tenant management throughout the Authority. He believed it would be best to initiate this in the development which seemed to have the greatest chance of success.

It would be difficult to draw many conclusions concerning the effectiveness of tenant management at the Iroquois Homes development in Louisville inasmuch as the Resident Management Corporation (RMC) signed a contract with the Housing Authority of Louisville less than one year ago, in July 1978. However, there have been several changes since the institution of the RMC, such as the creation of twelve positions for residents. 12 The employment opportunities were made available through the Department of Housing and Urban Development and Target Projects Program (TPP). The positions are in the management office, social services and the day care center.

In July 1978, when the RMC signed the management contract with the Authority, the vacancy rate was 18 percent. As of March 1979, the vacancy rate was five percent, according to data supplied by the Housing Authority of Louisville (HAL). It appears most of these vacant units have been filled by lower income tenants. The following illustrates why this is probable: 
The average per unit per month (PUM) income has decreased during the tenure of the RMC from $\$ 51.13$ in July 1978 , to $\$ 47.48$ in February 1979. This problem is primarily due to the failure of

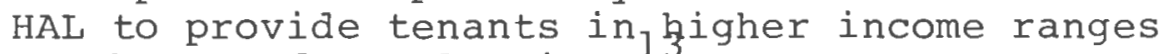
to the RMC for selection.

It may be determined from this comment that the RMC does not have the power to determine tenant selection on its own volition. The Authority screens prospective tenants first, and then sends these persons to the RMC for selection.

According to the information supplied by the Louisville Housing Authority, it is in the process of revising its admissions and occupancy policy for income guidelines. It is clear they intend to increase the number of higher (moderate) income tenants at the RMC development. This action would be consistent with one of the stated objectives of the Demonstration Program, which is to increase the project income. If the Authority's new policy completely eliminates lower income households from becoming eligible for tenancy at the Iroquois Homes development, then tenant management will cease to be an alternative means of housing low income people in Louisville.

Mixing the economic classes of the lower incomes in public housing can be a viable means of using positive role models to encourage those who see no way out of the poverty cycle. However, if tenant management developments become the exclusive home of the higher income poor, then the problem of housing low income has not been solved, but rather pushed aside. 
Louisville was allocated approximately $20 \%$ of the TPP, and modernization funds given by Department of Housing and Urban Development. This amounts to $\$ 4.2$ million. It should be understood at this point that the majority of the funding for the demonstration program originates from these two sources. The financial commitment from the Housing Authorities is minimal.

There seems to have been some difficulty in administering the $\$ 4.2$ million grant given to the Authority, according to the HAL coordinator who stated:

One of the greatest problems in the tenant management demonstration locally, was in the administration of the $\$ 3.5$ million of modernization improvements which accompanied the $\$ 671,400$ TPP grant. Unfortunately, there was much mismanagement in administration of these contracts by HAL. 14

It isn't known to what extent this problem exists, or how it will effect the RMC in Louisville in the long run. one thing is definite; since the demonstration represents 20 percent of the total units in the program, how well the RMC works out in Louisville will have a major effect on the future of this model of tenant management.

\section{Stella Wright Homes, Newark, New Jersey}

In addition to the six demonstration sites which are part of the National Demonstration Project, Newark, New Jersey, has experimented with the concept of tenant management. The origins of tenant management at stella Wright Homes in Newark are very similar in many respects to that of the st. Louis tenant management experience. 
The Newark Housing Authority (NHA) and the Stella Wright residents were involved in a law suit which had evolved from a rent strike. In the Mccray v. Beatty case, the court held that one of the major conditions for ending the rent strike would be to allow the tenants to establish a tenant management organization to manage the Stella Wright development. In order to accomplish this end, HUD provided $\$ 1.5$ million in TPP funds, and $\$ 8.9$ million in Modernization funds. The TPP monies were utilized to initiate the tenant management program and improve the security system. Modernization monies were used to improve the physical conditions at the development. The most startling changes which occurred in the first 18 months of the TMC's operating was that the average PUM almost doubled, from $\$ 47.00$ to $\$ 92.00$, and that more than 800 units, which were previously vacant, were leased to new residents.

The following is a list of accomplishments, according to Mr. E. James Bradley, the TPP Coordinator at Stella Wright Homes:

1. The vacancies have been reduced from $78 \%$ to less than 28 in July 1978. This was accomplished with the money provided by Modernization.

2. The maintenance staff performance and productivity have improved. The grounds are markedly cleaner than before.

3. The collecting of rents throughout the NHA has been 
centralized and computerized. The TMC at Stella Wright isn't responsible for rent collection, only for dealing with rent delinquencies. Mr. Bradley stated that,

"By removing, for the most part, this decision making process from the manager, i.e., who should or should not be sued, the NHA has increased collection of current delinquencies and evicted tenants who previously have been able to build up large balances by entering stipulation Agreements. This process has also increased our ability to bring "better" higher paying new residents into public housing."15

4. TPP monies have been used to install a 24 hour closed circuit television, apartment intercoms and hire a tenant security patrol.

Without the infusion of TPP/MOD monies, none of the improvements to the physical plant or the establishment of the TMC would have been possible. In fact, if the vacancies had not been cut so drastically, and the PUM increased to nearly double, the staff salaries of the TMC could not have been included in the operating budget. So in effect, what is occurring in part, is that higher (moderate) income residents are being moved in, rental income is increasing, low income households are not being directed to stella Wright as frequently (thereby less housing opportunity) if at all and tenant management seems to be working well for these moderate income households.

In the first chapter, mention was made of the comments of Senator Wagner during the legislative hearings of the Housing Act of 1937. The Senator said the bill 
cannot help those who cannot pay the rent less the subsidy allowed. More than forty years later, the same type of considerations are being made in Newark, New Jersey and Louisville, Kentucky.

If there is a successful outcome in Newark, and it seems that by the indicators used that it is working, it is a reflection not so much of instituting tenant management, but of the infusion of TPP/MOD monies, and of the Authority's policy to attract more higher income tenants. As mentioned previously, attracting more higher income tenants is essential, but it should not be done to the exclusion of the lowest income households.

The TMC at Stella Wright doesn't deal with rent collections, and in effect cannot determine what problems may be occurring in certain households which contribute to rent delinquencies. The tenants who had previously been permitted excessive rent arrears, could not be completely blamed for that situation. The manager of the development has a responsibility to ensure rent is paid promptly, or at least that certain arrangement are made, such as a rent schedule.

One of the purposes of combining the "hard" and "soft" management programs at one location was to enable the TMC to obtain a better understanding of the tenants on a personal basis, and create a more total community. In Newark, there is a separation of various functions such as rent collection. This separation of the functions is contrary to the original goals as stated by Mr. Baron. 
The Newark Housing Authority established a computer system which automatically forwards an eviction notice if rental payment is not made by a certain date. This type of mechanism does not permit any compromise or better understanding with tenant management. By evicting families with hardships, the Authority is, in effect, transferring the problems to other locations.

There have been some positive accomplishments at the Stella Wright development. This is not to be denied. However, the dilemma of housing the low income families with problems must be faced and dealt with. Bringing in higher (moderate) income tenants to fill the vacancies, is not by itself the complete solution.

\section{The Target Projects and Modernization Programs}

An essential ingredient in the Tenant Management Demonstration Program is the combination of TPP with Modernization grants from the Department of Housing and Urban Development. TPP was established to achieve the following goals:

Improvements in:

1. Management

2. Fiscal conditions

3. Deferred maintenance

4. Security

5. Resident employment and

6. Community servicel6

The Modernization program began in 1968. The federal government, through this program, was attempting to deal with rising operating costs and inflation, as well as deferred maintenance problems in public housing. Modernization funds have been used to reduce the vacancy problem at the 
developments as has been illustrated by the Louisville and Newark developments.

The allocation of $\$ 20.2$ million for both TPP and MOD has indeed shown improvements, at least in the sites described. The improvements are seen in such indicators as reductions in vacancies, turnover rates and vandalism; and increases in project rental income and higher income tenants choosing to live within these developments.

Table 6

MOD and TPP Allocations to Participating Sites:

National Tenant Management Demonstration Program

\begin{tabular}{|c|c|c|c|}
\hline Site & $\begin{array}{c}\text { Target Projects } \\
\text { Program }\end{array}$ & $\begin{array}{l}\text { Moderri- } \\
\text { ization }\end{array}$ & Total \\
\hline $\begin{array}{l}\text { Jersey City, N.J. } \\
\text { A. Harry Moore } \\
\text { Currie Woods } \\
\text { Louisville, Ky. } \\
\text { New Haven, Conn. } \\
\text { New Orleans, La. } \\
\text { Oklahoma City, Ok. } \\
\text { Rochester, N.X. }\end{array}$ & $\begin{array}{r}580,700 \\
581,000 \\
671,400 \\
442,100 \\
2,010,500 \\
514,300 \\
400,000\end{array}$ & $\begin{array}{r}\$ \quad 997,000 \\
1,015,000 \\
3,500,000 \\
1,650,000 \\
6,524,000 \\
1,007,000 \\
307,000\end{array}$ & $\begin{array}{r}1,577,700 \\
1,596,000 \\
4,171,400 \\
2,092,100 \\
8,534,500 \\
1,521,300 \\
707,000\end{array}$ \\
\hline Total & $\$ 5,200,000$ & $\$ 15,000,000$ & $\$ 20,200,000$ \\
\hline
\end{tabular}

Source: First Report on Tenant Management, Manpower Demonstration Research Corporation, New York City, N.Y. (December 1977).

This chapter has focused on an alternative model to the Bromley Heath Tenant Management Corporation. Although the basic framework of the St. Louis tenant management organization (and Louisville and Newark) is similar to that of Bromley Heath, several important differences exist. 
The following discussion will serve as a summary of the st. Louis model (including Louisville and Newark), and Chapter 5 will compare and contrast these two approaches.

The original intent of the St. Louis model was to combine the "soft" and "hard" management functions under one umbrella. In this way, the management would be in greater contact with the social needs of the development, and obtain a better understanding of the individual problems of families. This approach would seem to indicate that management would give consideration to financially-pressing issues with which a family may find itself at rent payment time, and set up a payment schedule.

However, in the Iroquois Homes development, the power to determine tenant selection resides with the Housing Authority of Louisville. In the Stella Wright Homes development in Newark, rent collection resides in the central office, and not with the local tenant management organization.

If these two functions are carried out apart from the tenant management decision-making process, it becomes difficult to develop an understanding of the problems of individual families, or create a sense of homogeneity. There is no mechanism for examining each non-payment of rent case. 
In St. Louis, an innovative approach to generating employment was instituted. Training was provided in food preparation and nurse practitioning, as well as other fields. Arrangements were made with the state Division of Family Services to provide day care and related services. This was combined with funding from HUD, HEW, AND Labor to create training in labor market areas which are in demand.

In the Iroquois Homes development, the Housing Authority (Louisville) is in the process of redefining its policy which would steer more higher (moderate) income tenants to the apartments. If this policy is carried out to its full extent, then low income households will no longer be selected for this development, in an attempt to increase the rental income. Further, if this philosophy permeates other Housing Authorities, what will the outcome be for low income tenants? The results will, of course, be similar to what has happened in many other national housing programs; the moderate income households will receive greater benefits than the low income groups. To say that tenant management works well in public housing due to the indicators used in the St. Louis and Newark developments would not be fallacious. However, in these developments, the social costs in bringing about success is often too high. A policy of uncompromising eviction and divorcing rent collection and tenant selection from tenant management control, does not create a cohesive 
community environment. Nor does it bring to management the understanding of the problems and social needs of families within the development. For example, if the tenants management organization does not exercise control over rent collection, how can management achieve the awareness of financial problems plaguing some households? An important funding source for the National Tenant Management Demonstration Program is TPP and MOD. Without these sources, tenant management would not have been possible. If this funding were to end abruptly, there would be little hope that the TMC's could continue as viable organizations unless the individual housing authorities agree to fund them with their own expenses. Without a firm commitment from the housing authority as well as the involvement of dedicated tenants, tenant management will not work.

The St. Louis model for tenant management seems to have several major problems such as failure to provide an adequate or real decentralization of management responsibility, no provision for a case-by-case approach to the problem of rent payment, and an eviction process which replaces low income tenants with moderately-low income tenants. This model still leaves one to ponder how low income households should be dealt with. 


\section{ENDNOTES}

Chapter IV

1. Richard D. Baron, Tenant Management: A Rationale for a National Demonstration of Management Innovation, (St. Louis, Mo.: By the Author, 1975), p. 12 .

2. Ibid., p. 24 .

3. Ibid., p. 51 .

4. St. Louis, MO, St. Louis Housing Authority. St. Louis Housing Authority Annual Report 1974-75, (1975), p. 13 .

5. Baron, Tenant Management: A Rationale for a National Demonstration of Management Innovation, p. 53.

6. Ibid.

7. Ibid., p. 76 .

8. Ibid., p. 77.

9. Manpower Demonstration Research Corporation, First Annual Report on the National Tenant Management Demonstration (New York: By the Author, 1977), p. 18.

10. Ibid., p. 14 .

11. Correspondence with Andrea Duncan, Resident Management Coordinator, Housing Authority of Louisville, Louisville, Kentucky, 20 March 1979.

12. Ibid., p. 2 .

13. Ibid., p. 3 .

14. Ibid. 
15. Newark, New Jersey, Newark Redevelopment Authority, E. James Bradley, The New Stella Wright Homes Final TPP Report, (July 1978), p。 8.

16. Veronica Chickadel, "NAHRO TPP Services Program Reports First Year Accomplishments, Plans for Second Year Activities," Journal of Housing (November 1976): 551 . 
V. COMPARISON AND EVALUATIVE ANALYSIS

OF THE TWO MODELS OF TENANT MANAGEMENT

In order to evaluate the methods which each model follows, it is necessary to explain the underlining, basic tenets or philosophies which gave birth to these two concepts. The TMC for Bromley Heath was developed by Mr. Ellis Ash, a former Head Administrator of the Boston Housing Authority. The Bromley Heath model began with the premise their aren't any problem families living in the development, but rather many families with problems. Also, each of these families has a problem which is unique, and must be considered on a case-by-case basis, especially in relation to rent delinquency problems. The TMC at Bromley takes a socially-oriented, real estate management approach to tenant management.

The model developed by Mr. Richard Baron, although similar in some respects to the Bromley concept, is a more business oriented approach. This was illustrated by the following statement:

This experiment in resident management has demonstrated that public housing can be well managed, despite severe operating deficits, by disciplined, trained residents who, without compromise, are prepared to enforce community development standards against those who persist with unjustified rent delinquencies or anti-social behavior. 
There seems to be more of a hard line approach to delinquent tenants and those with "anti-social behavior." There is no real explanation offered of what constitutes this type of behavior. It would appear this would be the equivalent to "problem families" in the development.

The Stella Wright development which was discussed in chapter IV, has a tenant management approach structured similarly to the st. Louis model. The manner in which the Newark Housing Authority (NHA) deals with rent delinquencies contrasts sharply with that of the Bromley Heath TMC.

The following is an example of a method in which the TMC at Stella Wright deals with the problem of rent delinquency:

Collection of delinquent rents has also increased drastically because a great deal of subjectivity has been removed from the eviction process. Automatically rental delinquency forms are kicked out to tenants who do not pay their rent by the fifth day of the month and a notice of intent to refer to court for non-payment of rent after the tenth of the month.2

It should be recognized that this method of rent collection does not necessarily resemble other tenant management developments in the demonstration program. However, it does illustrate the lack of social concern which the st. Louis model seems to exhibit. The subjectivity mentioned here, and the no compromise discussed previously, could also represent an approach which deals with tenant problems case-by-case. Tenants who do not make payments by the required date will be evicted or the Newark Housing Authority 
will at least file a summary process suit. There will, of course, be instances where eviction of a tenant is necessary. However, the computerized procedure discussed above doesn't permit any discretion for unique tenant situations. There is no mechanism which has been developed here to allow for closer relationship between tenant and TMC.

An important issue raised indirectly here is; where will the evicted tenant go after removal? The Authority has eliminated a tenant who has been creating problems for them, but the city, society, and the tenant still have problems which need to be addressed.

Bromley Heath utilizes a case-by-case approach to rent delinquency problems. The management believes this method is necessary, since many times families do have legitimate financial problems, and a rent schedule can be arranged. It cannot be inferred that Bromley does not have rent delinquency problems simply by virtue of this approach. However, data for this was not available to be evaluated. It can only be stated that though rent delinquency is a problem at Bromley, there are relatively few instances of eviction for this reason.

Baron considers his model of tenant management a new means of helping to relieve severely distressed conventional public housing, and creating a sense of community within the development for its low income residents. Although this is one of the original goals, 
very low income households will not be the prime benefactors from the demonstration program in Louisville, Kentucky. As stated in Chapter IV, the Housing Authority in Louisville is in the process of revising its admission and occupancy policy for income limits at the site. By increasing the income limits, those who are truly indigent will not be given as many units as was previously available for them. If the Housing Authority is attempting to mix the income levels, this was not stated in the correspondence, only that there was a concern about the lower rental income level for the development. The Louisville Housing Authority is not deviating from the stated objective of the Demonstration Project, which is to increase project income. But in a broader context, the housing opportunities for very low income families are not being expanded to any significant degree. Conventional public housing is essentially the only government program that provides housing to very depressed families. 3 section 8 housing allowances do provide an opportunity for the indigent to receive subsidies, but there have been problems with landlords accepting families in their apartment building with section 8 rent certificates. In addition, there is a great deal of latitude in the upper limit on income for section 8 , which in reality reduces the number of rental subsidies which would accrue to very low income families. 
What Chester Hartman has stated several years

ago is still true today,

The truly poor (those with less than $\$ 3,500$

annual income in 1971) receive only one-sixth

as much benefit from federal housing aids

as do moderate or middle to high income families,

only 9 percent of the combined 4 amount received

by these higher income groups.

If the other TMC's follow the lead of the Newark and

Louisville Authorities with a policy of setting higher income guidelines, housing options for very low income families will be further decreased.

The TMC at Bromley Heath has the power to select tenants for the development provided the procedure utilized follows Housing Authority and HUD guidelines. The TMC also has its own waiting list which is separate and distinct from the waiting list for other Boston Housing Authority developments. The TMC is able to determine who, in its judgement, would be an asset to furthering the concept of tenant management at Bromley. Although the TMC at Bromley is endowed with tenant selection powers, there does not seem to be any evidence of a total shift to bring in all higher (moderate) income tenants. The management is attempting to make Bromley an attractive place to live for prospective tenants and is not attempting to recruit exclusively higher income tenants. In discussions with the Executive Director, it seems the TMC is interested in having an economic mix of tenants, and considers this to be essential in the stability of the community. There are few instances where tenants are 
removed from a unit because of exceeding income parameters. The TMC believes that if the tenant who does over the limit remains in the community, it can have a positive effect on other tenants.

As has been discussed in Chapter IV, the major source of funding for the National Tenant Management Demonstration Program has been the Target Projects Program (TPP) and the Modernization program. The local housing authorities (LHA) aren't required to make any significant financial commitment for their participation in the management program. The federal government would expect that if the demonstration is a success, then the housing authority would commence to fund the tenant management program, and possibly extend it to other developments. The LHA's are, to some extent, conduits for the funneling of federal monies. In his original proposal to HUD, Baron commented that LHA must be a willing participant in the management demonstration, and able to decentralize certain functions. ${ }^{5}$ Although they may be willing participants in terms of being recipients of TPP/MOD funds and monitoring the flow of funds to the tenant management program, one test of a real commitment is in determining how much funding the LHA will contribute once the initial monies are exhausted or terminated. It is too soon to see how this will evolve, but this will be an important indicator of a commitment by the LHA to furthering tenant management. 
Bromley Heath has more varied sources of funding. The BHA provides operating expenses to the TMC, the amount of which is determined jointly by the Housing Authority and the TMC. The TMC at Bromley has the power to apply for and receive grants. Through an Economic Development Administration (EDA) given to the BHA for Bromley, modernization work is now being accomplished. The grant is for $\$ 630,000$ for the fiscal year 1978 .

The TMC at Bromley has a definite commitment from the Housing Authority in terms of funding, as well as a working relationship. This commitment is further substantiated by the fact that a new contract between the BHA and the TMC has been finalized (May 1979). Chapter II offers a full discussion of the new management contract. Thus, one major distinction between the two models is the funding sources and commitment of the LHA's involved. Bromley receives operating funds from the BHA and various federal agencies. Those sites involved in the demonstration project have yet to receive firm commitments from their respective LHA's, but they are receiving monies from the federal government in TPP/MOD programs.

Another significant difference is that Bromley Heath has the authority to make tenant selections, collect rent, perform income reviews and evict tenants, if necessary. The Boston Housing Authority has decentralized these powers to the TMC at Bromley, whereas the Authorities in Newark and Louisville did not give the TMC's the authority to perform such functions. 
The idea of utilizing building/lane managers was established originally in the St. Louis TMC by Mr. Baron. It seems to be a significant link in the organizational structure between the TMC management and the residents in the development. As was discussed in Chapter IV, the building or lane manager is responsible for approximately 125 units, and works with a custodian to arrange a daily work plan. This manager distributes information from the TMC to the residents, as well as performs the reverse function. She/he transmits grievances and other problems from the tenants to the TMC management for reconciliation. The most significant function of this manager, in terms of cost to the development, appears to be when a unit becomes vacant. The TMC is quickly advised by the manager, and efforts made to expedite the unit for re-rental. The benefit here is that the units do not remain vacant for very long which reduces the problem of vandalism. Further, when a unit becomes vacant, the security patrol is notified so it can provide additional surveillance. Since the building and lane managers live in the buildings she/he would tend to recognize the tenants, and unknown persons in the building or vicinity would be identified more readily.

Bromley Heath doesn't have this type of manager in their buildings at the present time. However, in Bromley's 1978 Urban Initiatives (UI) proposal, they did discuss the possibility of establishing the position of "Building 
Captains." This was contingent upon the acceptance and the granting of funding. The Columbia Point development was the only one to receive HUD money that year in Boston for the UI, so it is still a goal which Bromley Heath is seeking to achieve.

The Baron Model has developed, for the purpose of evaluation of the Demonstration program, a good quantitative feedback mechanism. That is, good measurements or indicators of change data would be collected in order to determine the Demonstration's effectiveness. "Felt needs" or qualitative data will be included as well as interviews with residents of the housing developments. This is an important part of determining future policy questions. How well is the program working? This is the first question which will be asked, and invariably quantitative data is required. Qualitative information may be readily available, but policy considerations on such issues as whether or not to continue funding of the program will turn, many times, on quantitative indicators of change.

The BHA, although able to provide a wealth of information on Bromley, did not have recent information on the number of tenants employed, crime related to the development (they were working on it), as well as good, accurate occupancy statistics. It was not possible to obtain information on many functions related to the individual developments due to HUD regulations which require authority-wide statistics. However, the BHA is in 
the process of making available a development profile for data collection purposes. Several BHA staff members have mentioned difficulty in obtaining information on Bromley Heath.

If Bromley Heath (or St. Louis) is to be considered a model to be used in the future, it is necessary that information flows more smoothly between the Housing Authority and the TMC. It is important to determine if and how the concept of tenant management is transferable to other housing developments, if the problems of conventional public housing are to be dealt with. Ellis Ash has commented that LHA's and HUD must accept the fact that mistakes will be made in the administration of tenant management, just as the BHA and HUD have made mistakes in new programs and concepts. Some leeway should be given here. Ash further stated that it should be recognized that the LHA is, to a large degree, using the tenants to fulfill LHA responsibilities, and should therefore allow them as much lattitude as they would themselves. 6

\section{Has Tenant Management at Bromley Heath}

Changed the Development for the Better?

Before the TMC began operations at Bromley Heath, there existed a great deal of hostility between the manager and the residents (see Chapter II). Trash littered the courtyards and hallways, and auto junks were in the parking spaces. Crime was very common (see Chapter's II and 
III), police protection was inadequate, maintenance was lax and workers were not cooperative with tenants (and vice versa) and vacancy rates were high. Today, many of these problems have been eliminated or at least curbed. Residents still, of course, have complaints about management, but the extreme hostile relationship which had existed seems to be gone. Tenants have raised their expectations greatly since the TMC took over the management responsibilities, expecting "more" because the tenants are "in charge." The TMC greatly reduced the lag time which was required to answer resident complaints. The crime problem at Bromley Heath has been greatly reduced as shown in Chapter III. The majority of the credit for the crime reduction must be given to the Boston Police Team Patrol Unit of District 2, as well as the Bromley Heath Resident Patrol. The cooperation between these two groups has created a safer community for its residents. However, it should not be thought that criminal activity has been eliminated completely from the area. However, it has been reduced enough to permit people to walk around at night.

The vacancy problem at Bromley still exists, but as was mentioned in Chapter III, many other variables are included which would preclude drawing any correlation between the tenant management organization and the vacancy problem. There are, however, efforts to modernize 24 units which were previously burned-out. These will be 
combined (breakthrough) to create 12 new units.

Many of these vacant units are one-bedroom

units. Some are on the first and seventh floors and many vacancies exist where community space is lacking. These aren't just problems of a lack of funding, but also involve security, management and density issues. If these issues can be dealt with in a comprehensive manner, then the vacancy problem could also be resolved.

Although data was not available for rent delinquencies at Bromley Heath, there are problems here that should be looked at closer by the TMC and the BHA. Data from the TMC on delinquencies should be supplied to the BHA in order to permit the Authority to construct a program evaluation of the TMC progress.

Evictions, used as a final resort, are not a common occurrance at Bromley. Eviction at the Newark TMC was a common method of dealing with the residents. According to a staff member at Bromley Heath, the use of direct vendor payments has helped keep the number of evictions down. Vendor payments are received from a governmental agency such as the Department of Welfare for AFDC, and are mailed directly to the TMC for rent payment. This method has been able to clear up a great deal of the rent arrearages which have accumulated over the years. The TMC did take over a large number of rent arrearages at the beginning.

Finally, employment generation from the TMC has 
enabled some residents to obtain jobs. However, it is not known what percentage of the Bromley residents utilize outside, on-the-job-training programs or classroom training to gain skills to enter the labor market. This is another area in which important data should be collected and evaluated. This is an important, evaluative devise to test the idea that economic mix of unemployed and employed households has a positive effect. of course, other factors should be included, such as the provision of day care, type of training and the time at which the training is offered, among other variables. Bromley Heath has created many significant changes with the use of tenant management, as has been discussed here. However, a more effective information system is necessary in order to be able to obtain a quantitative evaluation of the program. 
ENDNOTES

Chapter V

1. Richard D. Baron, Tenant Management: A Rationale

for a National Demonstration of Management

Innovation, (St. Louis, MO: by the Author, 1975), p. 8 .

2. Newark, New Jersey, Newark Redevelopment Authority,

E. James Bradley, The New Stella Wright Homes -

Final TPP Report, (July 1978), p. 8 .

3. Chester Hartman, Housing and Social Policy,

(Englewood Cliffs, N.J.: Prentice Hall, 1975),

p. 160 .

4. Ibid.

5. Baron, Tenant Management: A Rationale for a National

Demonstration of Management Innovation, p. 90.

6. Interview with Ellis Ash, former Head Administrator

of Boston Housing Authority, present consultant to

Bromley Heath TMC, Boston, Massachusetts, 16 February 1979. 


\section{RECOMMENDATIONS AND CONCLUSIONS}

This paper has shown some of the major problems facing conventional public housing. The issues of management and finance of public housing have proven to be central to seeking a solution to the physical and social neglect in urban public housing developments.

There is, as this paper has suggested an alternative method of public housing management which can help to alleviate some of the financial problems of public housing and social needs of its residents. The operation of this alternative method, tenant management, cannot and should not be thought of as the single solution for solving the problems caused by so many years of neglect. There is still a great need for an adequate level of operating and capital improvement expenses, to turn conventional public housing around.

The effectiveness of several models of tenant management have been examined. Although there is a lack of available data on individual development expenses and revenues, rent delinquencies and turnover rates, tenant management at Bromley Heath was evaluated with both quantitative and qualitative data. The general conclusion is that tenant management has been an effective means of dealing with some of the problems which have traditionally 
plagued urban public housing. Based on the research in this paper, the following conclusions have been drawn concerning tenant management at Bromley Heath in Boston and the St. Louis model.

one major positive change which occurred, with the establishment of tenant management, was the improvement of the working relationship between the maintenance workers (management) and the tenants. At Bromley Heath prior to the establishment of tenant management, there was a great deal of animosity between these two groups. (See Chapter I for a full discussion of the tenant hostility cycle.) The tenants had thought that management was not concerned about their welfare or the physical condition of the housing development. Some tenants, after having exhausted formal channels without success in an attempt to make management perform certain functions without success, resorted to verbal and physical abuse of the maintenance staff. Other individuals directed their hostility toward the housing development itself which resulted in vandalism and carelessness.

The cost of dealing with maintenance repairs resulting from vandalism and carelessness was very high. The Trans Urban East study found that in 1970 alone, 6,900 panes of glass had been broken and were replaced. There are additional acts of vandalism which were costly and are discussed in chapter II. After the establishment of the tenant management corporation at Bromley Heath, much of 
hostility which existed between tenants and maintenance workers ended. However, not all acts of violence and vandalism ended at Bromley Heath. This was due partly to criminal activity by persons from outside the housing development. In 1975, the community security patrol was established with CETA Funds at Bromley Heath. This provided a foot-patrol for the development for the first time. In 1976, Boston Police Department, instituted the Team Patrol Unit to operate in the Mission Hill and Bromley Heath areas. These two groups, working together, were able to reduce the incidents of crime drastically as was shown by Table 3 and Figures 3,4 and 5 .

Table 3 shows that prior to instituting the security patrol and the Team Patrol Units, both reported crime against persons and property were higher. In May 1974, there were 8 crimes against persons while in May 1975, there were 29. In May 1978, this total dropped to 8. The statistics for crimes against property also show decreases, though not of the same magnitude. In August 1974, there were 33 crimes against property, while in August 1976, there were only 11. In August 1978, there were only 16 crimes against property reported. The number of crimes has been reduced especially crime against persons and robbery in particular. The tenant management security patrol and the Boston Police Team Patrol Unit have contributed to reducing crime at Bromley and making it safe for residents to move about the development. 
Another positive effect of tenant management has been the establishment of specific procedures which the maintenance staff is required to follow. Prior to tenant management at Bromley, maintenance, by the staff, was haphazard, and tenants were required to clean the halls and stairways. This did not work well and resulted in halls filled with trash, a hazard to health. Moreover, there had been no set procedure established to ready a vacant unit for rental. This caused units to remain vacant for extended periods of time and prey for vandals. To replace the vandalized and burnt out units was costly. The potential rental income loss for the units was significant, especially with the developments facing such financial dilemmas.

The Tenant Management Corporation at Bromley has established procedures to have vacated units made ready for rerental promptly. This has reduced the problems of vandalism to the units and also reduced the expenses which would have been needed.

The TMC has generated approximately 40 jobs for residents, most of them positions in the maintenance department. Part of the general improvement in maintenance at the development could be related to the fact that the maintenance staff has a personal stake in the appearance of the grounds. Several management and clerical positions have been filled by residents of Bromley Heath in the Tenant Management Corporation. 
Overall, the Bromley Heath Tenant Management has been effective in eliminating the hostility situation which once existed, reducing the operating costs by reducing vandalism, and creating employment opportunities. Maintenance procedures have improved greatly and from observing the number of tenant gardens that exist, a sense of community seems to have developed.

Several observations should be made regarding the tenant management model developed by Mr: Baron. Although he sees tenant management as a means of dealing with the problems of housing low income persons in public housing, two housing developments in separate cities for which he was a consultant, (to set up a tenant management organization) have made concerted efforts to attract moderate income tenants. One of the developments is under the management of the Newark Housing Authority (NHA). The NHA has been evicting families who are delinquent in rent payments through a computerized system which eliminates the possibility of dealing with households on a case by case approach. Bromley Heath, however, does utilize a special consideration case by case approach to the problem of rent arrearages.

Baron has collected data on changes and established an evaluation mechanism for the National Tenant Management Demonstration Program. The changes which were recorded at the St. Louis developments where a tenant management organization was established are impressive. At the Carr 
Square development vacancies decreased from 45 to 5 in two years while rental income PUM increased from $\$ 42.26$ to $\$ 51.48$ from 1973 to 1975. Similarly, there were also decreases in vandalism in the development areas.

The present National Tenant Management Demonstration Program has been funded by HUD through TPP and MOD Programs and the Ford Foundation. It has not been in operation long enough to produce evaluative data. However, the Iroquois Homes in Louisville, Kentucky produced tentative data which indicated a decrease in PUM rental income. The coordinator of the program attributed this to a failure on the part of the Louisville Housing Authority to select higher income tenants for the project. It was further stated that the Authority is revising its tenant selection policy to steer higher income tenants to the tenant management development.

The St. Louis TMC established an employment training program at the various developments geared to the AFDC population. The funds for the program were appropriated from HEW, HUD, and the Department of Labor. No data was available to determine how effective the program was in reaching its goal (training AFDC persons with labor market skills), but it is an innovative approach to helping low income families gain marketable employment skills.

As mentioned in the previous Chapter, the st. Louis TMC utilizes a building or lane manager. This is an 
essential link between the management office and the residents. The building or lane manager distributes information to the residents on matters of concern to the development, and reports grievances to the tenant management staff as well as setting up the daily work schedule for the custodian. The manager is responsible for approximately 125 units and is probably familiar with the tenants which lessens the possibility of unknown persons entering the building.

The building or lane manager is responsible for notifying the TMC when a tenant vacates a unit. This in turn would alert the maintenance and security staff to begin their respective duties with regards to the vacant unit. This type of manager in a tenant management organization or any public housing development can be very effective in reducing vandalism, increasing maintenance productivity and acting as an information link between management and the residents.

The St. Louis (Newark, Louisville) model of tenant management has had positive effects on the developments in which it was established, if effectiveness is defined purely in terms of economic and fiscal impacts. PUM rental income in Stella Wright increased, vandalism decreased, the average income of new tenants was higher and eviction of rent delinquent tenants was common. The same situation was found in the St. Louis TMC's. If effectiveness is measured in regards to the ability to house very low 
income families, it has not succeeded. A major problem in public housing, especially the conventional type, has been the inability of the housing authority to provide quality housing for very low and low income households. Baron's model does increase occupancy rates and rental income, as well as decreasing crime. However, these are accomplished at the expense of many of the existing low income tenants who are unfortunate enough to be in arrears. Part of the large arrears in some cases, could have been the responsibility of the development manager for not being strict enough in demanding prompt rental payment.

By evicting tenants from low income housing, many of whom are there due to the economic pressures of a tight (and discriminatory) housing market, and replacing them with moderate income tenants, does not solve the housing problem for the evicted households. Eviction should be a last resort, not the first method of dealing with the problem as Baron has done. This is a serious flaw in the St. Louis tenant management model and for this reason, should not be considered an adequate tenant management prototype.

The Bromley Heath TMC has been given a major commitment by the Boston Housing Authority. A new contract was recently signed between the two parties for a five year period. This is the type of commitment which is needed if innovative approaches to dealing with public 
housing problems, such as tenant management are to become institutionalized.

Although tenant management at Bromley Heath has had some positive effects, the following are recommendations which, it is believed could help improve the functioning for tenant management for the $\mathrm{TMC}$, the BHA and the residents:

(1) The establishment of a better management information system between the Boston Housing Authority and the Bromley Heath TMC. The TMC would be required to submit reports on rent delinquency, rent collection rates, turnover rates, and maintenance expenses. This could be submitted on a monthly basis to either the Planning or Property Management Office to enable a systematic evaluation to be conducted and also establish a good data bank.

(2) The development of a workshop program to educate all families living in the development, in the use of dwelling equipment and homemaking practices. Without a program such as this, the social needs of the residents and the realities of present public housing will continue to be ignored.

(3) A program to increase job training and employment opportunities for the residents should be instituted. Grants may be available 
through various public and private agencies for this purpose. Tenants should be made aware of the potential for economic mobility.

(4) Bromley Heath should consider the establishment of the position of building or lane manager in their buildings. This could be accomplished on a gradual basis in order to monitor its effectiveness.

(5) An important partner in furthering tenant management could be the State of Massachusetts, particularly the Department of Community Affairs (DCA). DCA should begin to take a more active role in encouraging tenant management in such state operated family housing programs as Chapter 200 and Chapter 705 as well as encourage further research, and possible development of tenant management as a management prototype.

(6) DCA should encourage LHA's to become involved with tenant management. Not all LHA's nor all developments would be able to accommodate a tenant management corporation. However, depending on the specific circumstances of the development, some level or form of tenant management may be instituted. Appendix C provides a general outline of the steps which would lead to the formation of a tenant management organization. 
APPENDIX A

Table 7

Occupancy Rates for Columbia Point

$1974-1979$

\begin{tabular}{c|c|c|c}
\hline Total Units & Units Occupied & Percent Occupied & Date \\
\hline 1370 & 954 & 70.0 & May 74 \\
1370 & 947 & 69.0 & Oct. 74 \\
1370 & 794 & 58.0 & May 75 \\
1370 & 687 & 50.0 & Oct. 75 \\
1370 & 650 & 47.0 & Jan. 76 \\
752 & 479 & 64.0 & May 77 \\
752 & 453 & 63.0 & Oct. 77 \\
651 & 312 & 57.0 & May 78 \\
677 & 385 & 57.5 & Oct. 78 \\
670 & 385 & Feb. 79 \\
\hline
\end{tabular}

Source: Boston, Massachusetts, Boston Housing Authority Data from Minority Occupancy Report (1979). 


\section{APPENDIX A}

Figure 6

View of The Tenant Management Corporation

by The Boston Housing Authority

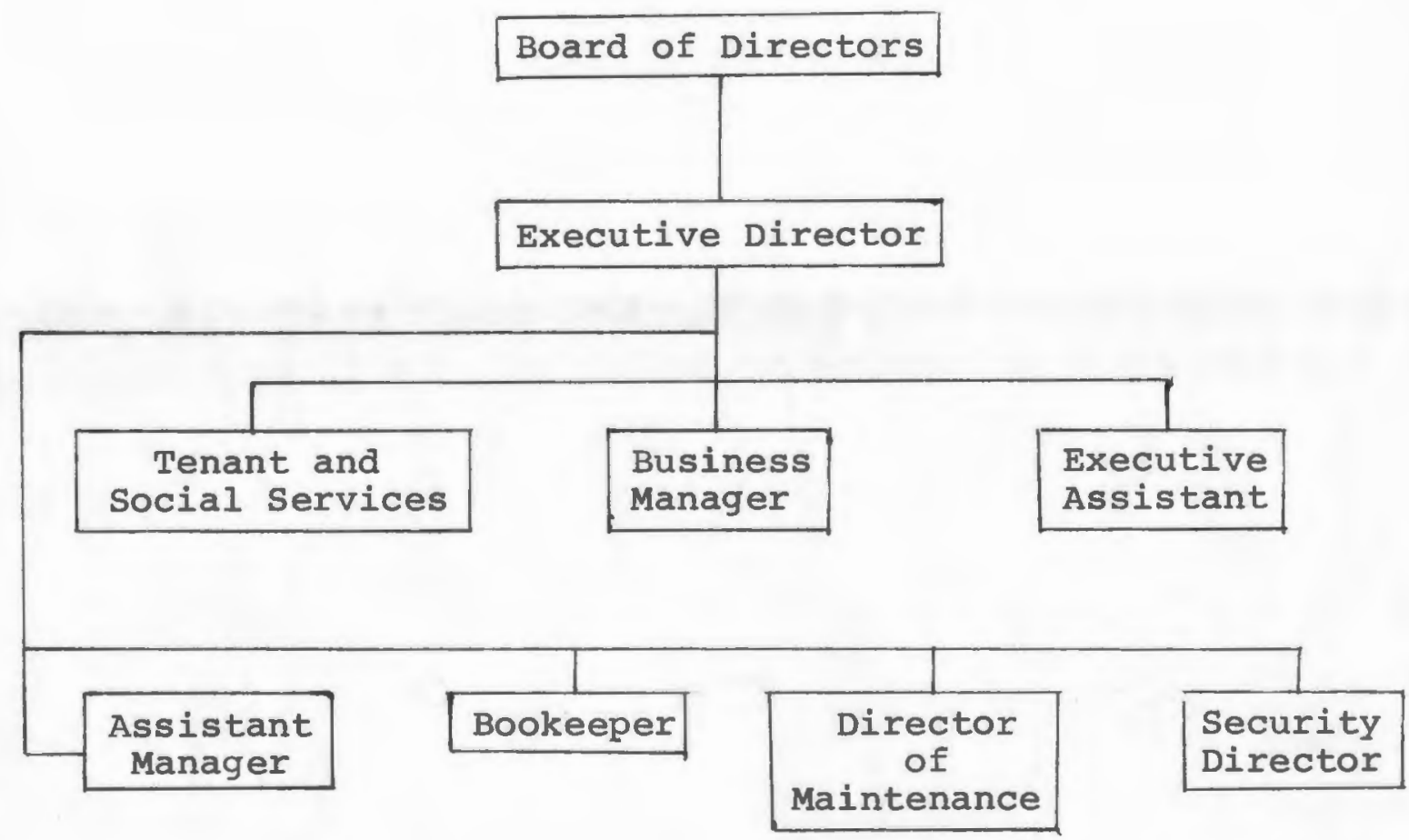




\section{APPENDIX A}

\section{Figure 7}

Tenant Management Corporation

view of The Organizational Structure

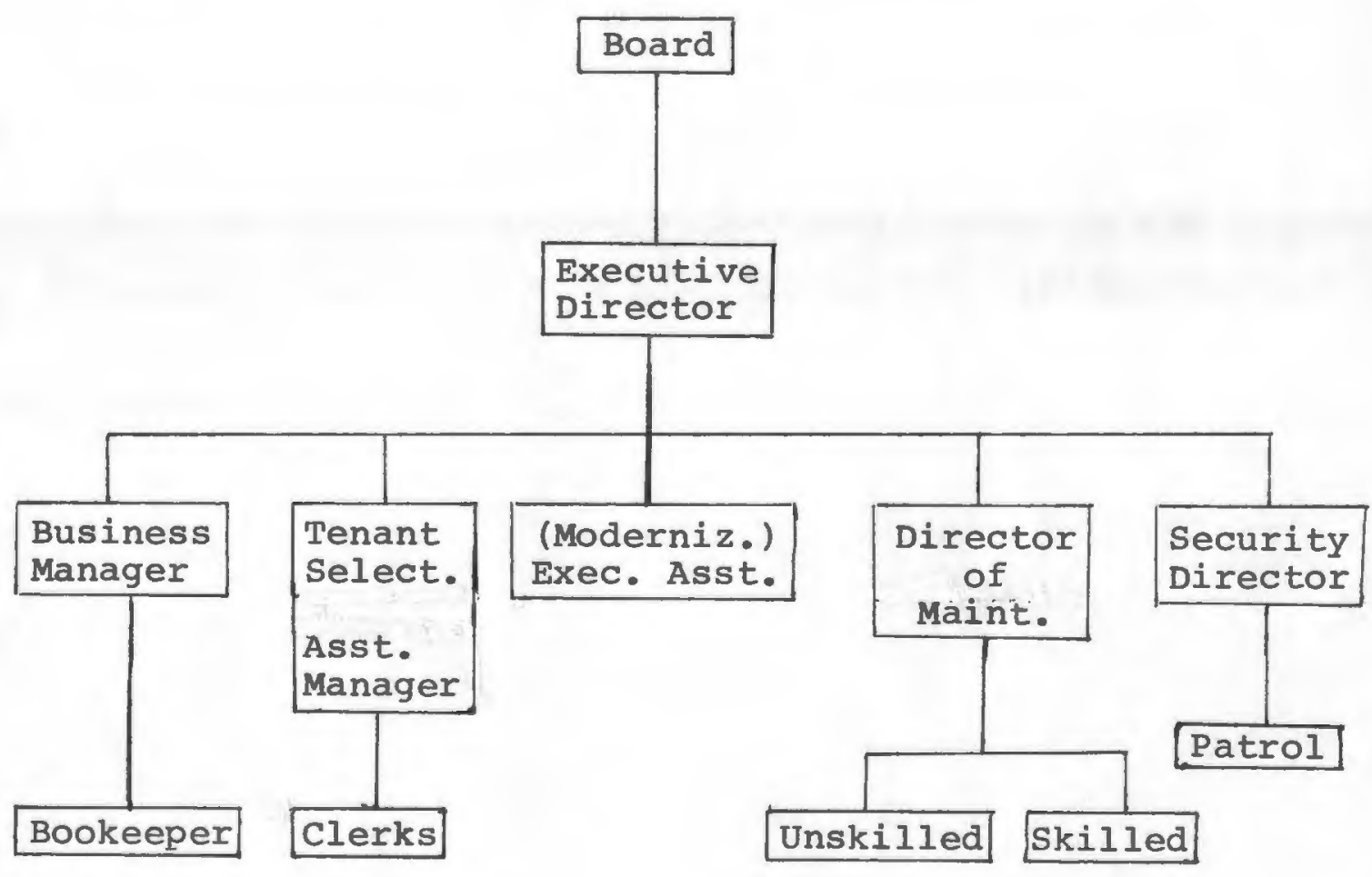




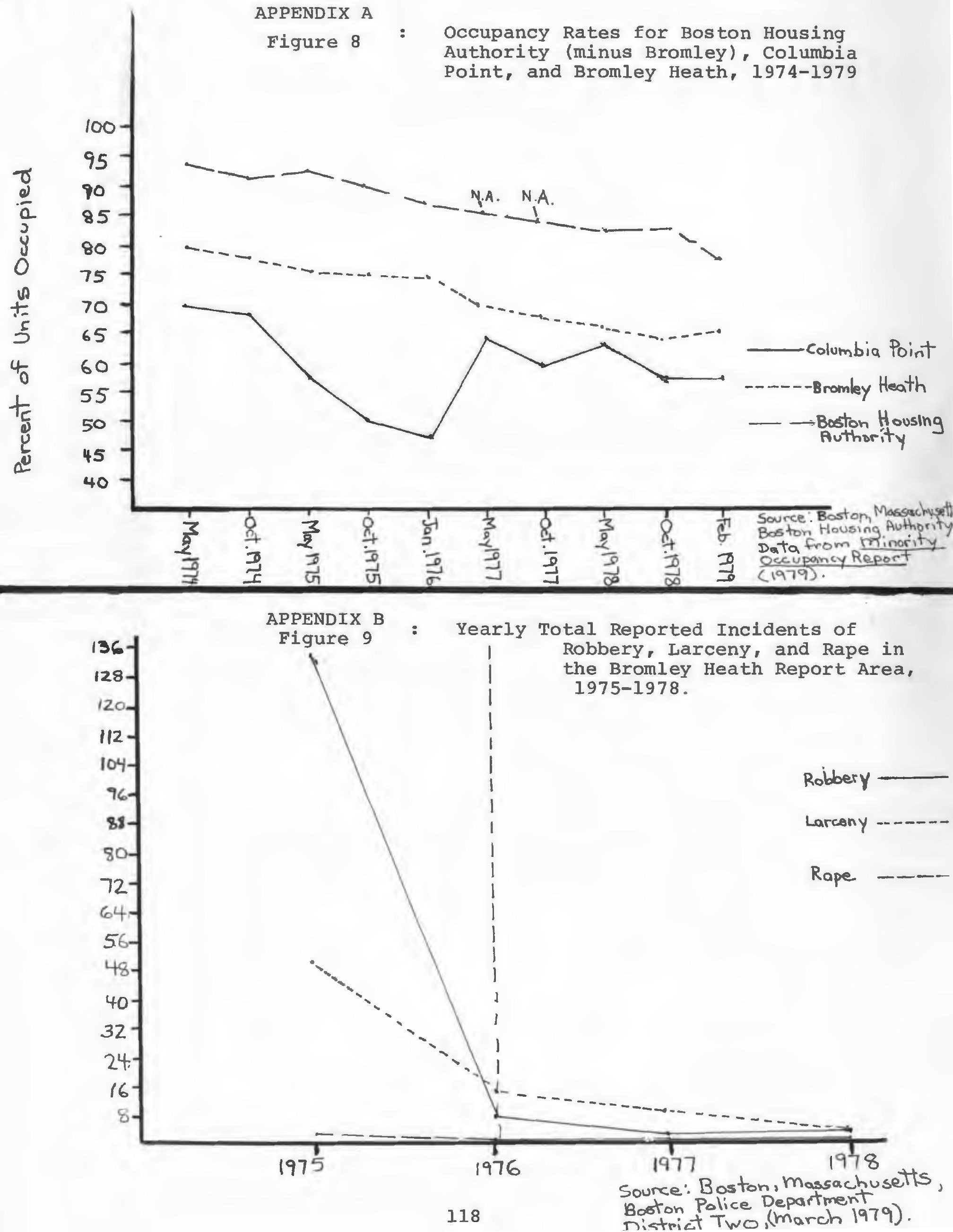




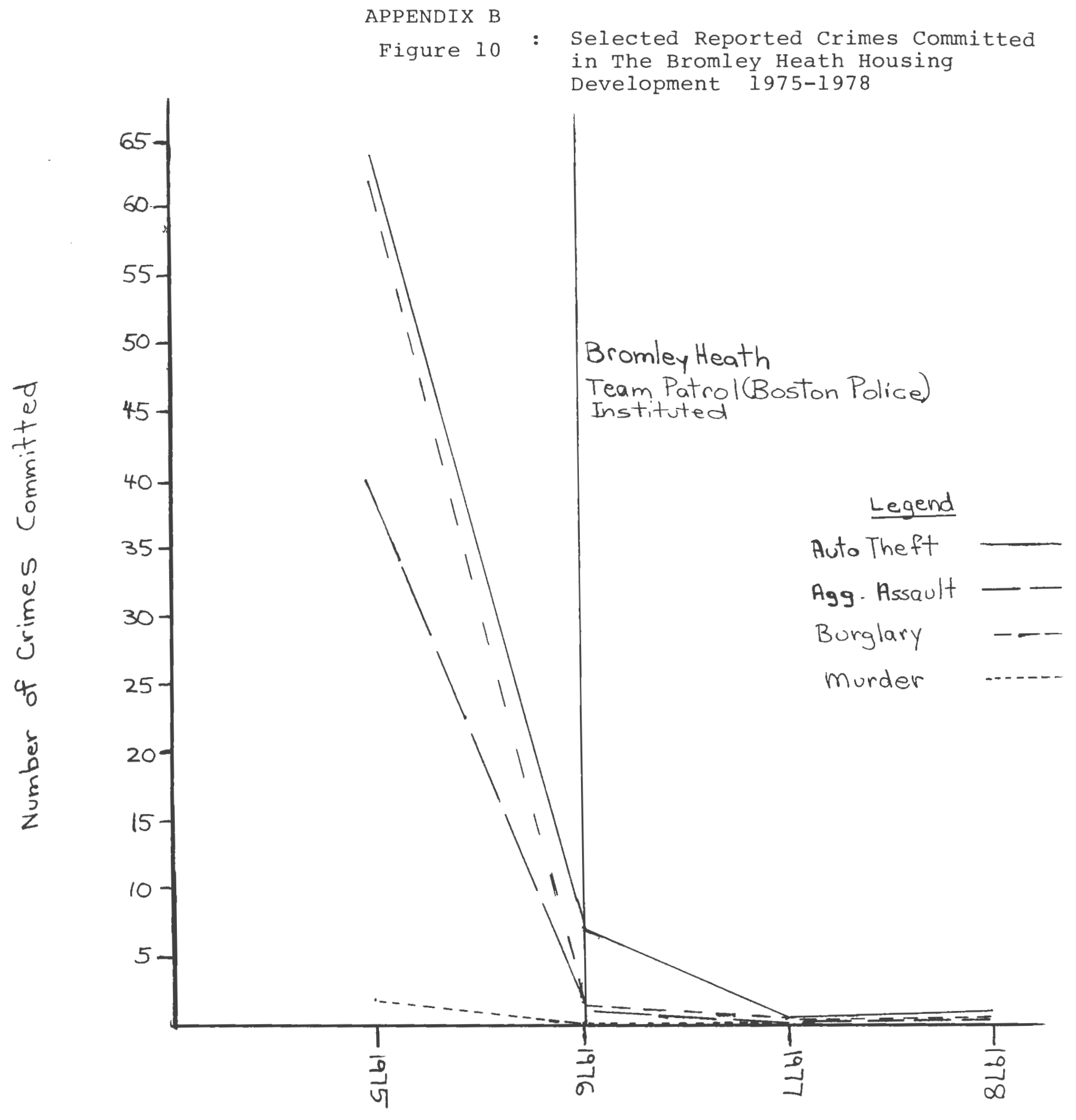

Source: Boston, Massachusetts, Boston Police Department, District Two, 1979. 


\section{APPENDIX B}

Table 8

Service Calls for the Bromley Heath

Report Area 1973-1978 (Selected Months)

\begin{tabular}{|c|c|c|c|c|c|c|c|}
\hline DATE & 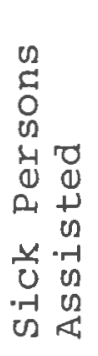 & 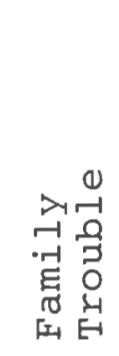 & 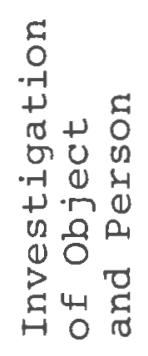 & 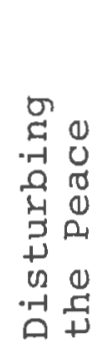 & 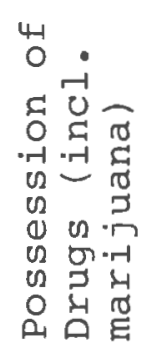 & 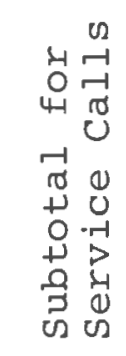 & 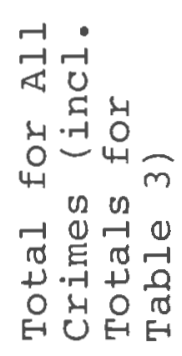 \\
\hline Jan. 73 & 5 & 21 & 26 & 6 & 0 & 58 & 58 \\
\hline May 73 & 0 & 11 & 57 & 11 & 0 & 79 & 79 \\
\hline Jan. 74 & 2 & 16 & 35 & 6 & 2 & 61 & 85 \\
\hline May 74 & 0 & 17 & 64 & 15 & 0 & 96 & 133 \\
\hline Aug. 74 & 11 & 21 & 87 & 19 & 0 & 138 & 188 \\
\hline Jan. 75 & 16 & 17 & 49 & 13 & 0 & 95 & 130 \\
\hline May 75 & 15 & 14 & 70 & 11 & 0 & 110 & 167 \\
\hline Jan. 76 & 8 & 0 & 0 & 0 & 0 & 8 & 29 \\
\hline May 76 & 4 & 0 & 2 & 1 & 0 & 7 & 26 \\
\hline Aug. 76 & 0 & 0 & 0 & 0 & 0 & 0 & 16 \\
\hline Jan. 77 & 4 & 0 & 0 & 0 & 2 & 6 & 26 \\
\hline May 77 & 2 & 0 & 0 & 0 & 0 & 2 & 26 \\
\hline Aug. 77 & 0 & 0 & 0 & 0 & 0 & 0 & 26 \\
\hline Jan. 78 & 3 & 0 & 1 & 0 & 2 & 6 & 26 \\
\hline May 78 & 0 & 0 & 0 & 0 & 0 & 0 & 30 \\
\hline Aug. 78 & 0 & 0 & 0 & 0 & 0 & 0 & 25 \\
\hline TOTALS & 70 & 117 & 391 & 82 & 6 & 666 & 1070 \\
\hline
\end{tabular}

Source: Boston, Massachusetts, Boston Police Department Crime Reports for the Boston Housing Authority, (1979). 


\section{APPENDIX C}

\section{Steps Leading to Tenant Management}

(1) An active tenant group or council is necessary as a first step. If no such group exists, one should be organized by the tenants or a community organizer. Tenants must be interested for tenant management to work.

(2) The cooperation of the local housing authority is essential. The LHA must be willing to set up a contract with the tenant management group which would transfer power, at least to some degree to the TMC.

(3) General tenant knowledge would be essential in budgeting, management, bookkeeping, and LHA decision making process. The transfer of responsibility for rent collection, maintenance, security, and other functions can be done on a gradual basis. The decision on how to transfer the responsibility should be determined by the LHA and tenant group.

(4) There should be a gradual phasing out of the old staff, which can be arranged with the LHA.

(5) It would be necessary to select a tenant staff and train the staff to assume the necessary functions of the management operation. 
(6) An interim committee would be set up to deal with transition of management responsibility, establishing the by-laws of the tenant management corporation and preparing for election of the board members.

(7) The initial board members must determine how each area of their responsibility will be handled such as tenant selection, social services, and the like. The Board must clearly understand the precise nature and extent of their power and responsibilities.

(8) Subcommittees can be formed to focus on specific area of concern such as employment, maintenance, or rent collection.

(9) The Staff and Board members should be in contact with each other on a regular basis. The by-laws of the corporation should establish the specific time frame for the necessary reporting time.

Source: Sections adapted from:

Massachusetts Department of Community Affairs, Interoffice Memo; "Bromley Heath Tenant Management Corporation." Boston, undated, early 1970s. 
SELECTED

BIBLIOGRAPHY

Abrams, Charles. The City is the Frontier. New York: Harper \& Row Publishers, 1965.

Ahlbrandt, Robert S., and Brophy, Paul C. "Management: An Important Element of the Housing Environment." Environment and Behavior 8 (December 1976) . :505-26.

Baron, Richard D., Tenant Management: A Rationale for a National Demonstration of Management Innovation. St. Louis, Mo: By the Author, 1975.

Becham, Robert, "Tenant Responsibility: Boston Provides a Showcase as Tenants Assume Leading Roles in the Design and Management of Public Housing." Journal of Housing (February 1973) :76-78.

Bingham, Richard D., and Kirkpatrick, Samuel A., "Providing Social Services for the Urban Poor; An Analysis of Public Housing Authorities in Large American Cities." Social Service Review 49 (March 1975) : 64-78.

Boston, Massachusetts, Boston Housing Authority, Consent Decree Subplan - VI F L : Prompt Rental or Securing of Vacant Units and Appendix - Discussion Paper : BHA Maintenance and Occupancy objectives, February 1979.

Boston, Massachusetts, Boston Housing Authority, "Minority Occupancy Reports, 1974-1979.

Bridges, John E. "Security System By the Residents, For the Residents, Under Way in Public Housing in Kansas City, Missouri." Journal of Housing 6 (June 1973) : 87-94.

Chicadel, Veronica, "NAHRO TPP Services Program Reports First Year Accomplishments, Plans for Second Year Activities." Journal of Housing (November 1976) : 551-53.

de Leeuw, Frank, Operating costs in Public Housing. Washington, D.C. :The Urban Institute, 1969. 
Fisher, Robert, 20 Years of Public Housing. New York: Harper and Bros. Publishers, 1959.

Friedman, Lawrence M. Government and Slum Housing. Chicago: Rand McNally \& Co., 1968.

Friedman, Lawrence M., "Public Housing and the Poor." In Housing Urban America, pp. 448-59. Edited by Jon Pynoos, Robert Schafer, and Chester $W$. Hartman. Chicago: Aldine Publishing Co., 1973.

Hailey, Mildred, Executive Director, Bromley Heath Tenant Management Corporation, Boston, Massachusetts. Interview, 2 February 1979.

Jamaica Plain Area Planning Action Council. "Registration for ABCD's Summer Jobs for Youth Opens." Community Forum, March 1979.

Knox, Michael D., Kolton, Marilyn S., and Dwarshius, Louis, "Community Development in Housing: Increasing Tenant Participation." Public Welfare (Summer $1974): 48-53$.

Manpower Demonstration Research Corporation. First Annual Report on the National Tenant Management Demonstration. New York: By the Author, 1977.

Massachusetts Department of Community Affairs, Interoffice Memo: "An Appraisal of Prospects for Tenant Participation in Management and Cooperative Housing." Boston, Undated, early 1970's.

Massachusetts Department of Community Affairs, Interoffice Memo: "Bromley Heath Tenant Management Corporation. Boston, Undated, early 1970's.

McDonnell, Timothy, The wagner Housing Act. Chicago: Loyola University Press, 1957.

Meehan, Eugene J., "Looking a Gift Horse in The Mouth: The Conventional Public Housing Program in St. Louis." Urban Affairs Quarterly 10 (June 1975): $423-63$.

Organization for Social and Technical Innovation. "Impact of Social Problems, Financing, and Construction on Management of Housing for Low Income Persons." Report prepared for HUD, Contract No. H-1057A, Cambridge, Massachusetts, 28 April 1970. 
"Revamp Underway at Bromley Heath" Jamaica Plain Citizen, 7 September 1978 , p. 1 .

Schorr, Alvin L., Slums and Social Insecurity. Washington, D.C. , 1966.

Smith, Paula Omega, "Rehabilitation of Public Housing: A Case Study of the Roger Williams Homes, Providence, Rhode Island." Master of Community Planning Thesis, University of Rhode Island, 1974.

Tenant Councils: Preparing the Climate. Housing Research and Development Department, University of Illinois, Urbana-Champaign, 1974.

Trans Urban East Inc., Final Report Regarding the Feasibility of Tenant Management at Bromley Heath Development. New York: By the Author, 1970.

U.S. Congress, Senate. Senator Robert Wagner reading a resolution of the American Federation of Hosiery Workers on proposed housing legislation. Cong., Sess., 7 May 1936. Congressional Record, Vol. 80.

U.S. Congress, Senate, Senator Robert Wagner speaking on proposed housing legislation (later to become Housing Act of 1937). Cong., Sess., 3 August 1937. Congressional Record, Vol. 80. 